\title{
GEOLOGIA DO GRÁBEN DE MARTINÓPOLE, ÁREA DE CAMPANÁRIO/PAULA PESSOA (GRANJA, CE): IMPLICAÇÕES NA EVOLUÇÃO LITOESTR ATI GRÁFICA E TECTONOMETAMÓRFICA DO NOROESTE DO CEARÁ
}

\author{
DIÓGENES C. OLIVEIRA*
}

\begin{abstract}
GEOLOGY OF THE MARTINÓPOLE GRABEN, IN THE CAMPANÁRIO/ PAULA PESSOA REGION (NEAR GRANJA, CE): IMPLICATIONS FOR THE TECTONOMETAMORPHIC AND LITHOSTRATIGRAPH1C EVOLUTION OF GEOLOGY OF NORTHWESTERN CEARÁ. The Martinópole Graben is located in the Northwestern part of Ceará State. A reconnaissance geologic mapping in an area between Campanário and Paula Pessoa cities allowed the stablishement of a lithostratigraphic and tectonometamorphic evolution of this Graben (Table 1). Six major stratigraphic units have been recognized in the study area (from bottom to top): Gnáissico-Migmatítico Complex, Martinópole Group, São José Group, Casinha Metasediments, and Jaibaras Group The Gnáissico-Migmatítico Complex underlies all other units and is characterized by an additional deformational phase $\left(\mathrm{D}_{\mathrm{n}-1}\right)$ which is not present on the Martinópole Graben. The São Joaquim Formation was excluded from the Martinópole Group due to its highly complex pattern of deformation and its different metamorphic grade (upper amphibolite with intermediate pressure facies potassium feldspar/sillimanite isograde and kyanite isograde). On the other hand within the Graben, the rocks have pointed out metamorphism in prehnite-pumpellyite facies(kaolinite + 2quartz $\leftrightarrows$ pyrophyllite $+\mathrm{H}_{2} \mathrm{O}$ ) to green schist facies (chlorite/biotite isograde or on the upper part of the stability of pyrophyllite). The Martinópole Group has been defined as a volcanoclastic unit, also containing minor amounts of volcanic and siliciclastic rocks. This group remains with the two original formations: Covão (bottom) and Santa Terezinha (top). The São José Group, which is distinguished by very low-grade metamorphic claystones and sandstones has an uncertain stratigraphic relationship with the Martinópole Group; the informal unit named Casinha Metasediments consists of diamictites with a pre-foliate pebbly framework. It can be correlated with the Olho d'Agua do Caboclo Formation (as defined by Hackspacher et al. 1988). The Jaibaras Group filled small pullapart basins and comprised molassic clastic wedges, that are represented by Massapé Formation conglomerates and by the fine clastic rocks of the Pacujá Formation, (both are Brazilian in age). All the units underwent several pulses of shear/faulting with different magnitudes, deformational mechanisms and age.
\end{abstract}

Keywords: Northwestern of State of Ceará, Martinópole Graben, tectonometamorphic evolution, metamorphism, stratigraphy, structural geology.

RESUMO Com base em mapeamento geológico de semidetalhe de uma área situada no "Gráben de Martinópole", entre as localidades de Campanário e Paula Pessoa (noroeste do Ceará), foi possível estabelecer uma evolucão litoestratigráfica e tectonometamórfica para essa região. As rochas do embasamento Complexo Gnáissico-Migmatítico revelam uma discordância estrutural em relação às litologias supracrustais e possuem exclusivamente a fase de deformação $\mathrm{D}_{\mathrm{n}-1}$. A Formação São Joaquim, até então pertencente ao Grupo Martinópole, foi desmembrada, em virtude de apresentar feições de deformação mais complexas e estar metamorfizada em fácies anfibolito superior (isógrada do feldspato potássico e da sillimanita), com pressões intermediárias (isógrada da cianita), o que não ocorre no referido grupo. Essa discordância estrutural-metamórfica é marcante na fase principal Dn, onde o restante das litologias do gráben acusam metamorfismo em fácies prehnita-pumpellyíta(caulinita +2 quartzo $\stackrel{\text { }}{\leftrightarrows}$ pirofilita $+\mathrm{H}_{2} \mathrm{O}$, sobretudo) até fácies xisto-verde inferior (isógrada da clorita e da biotita, ou na faixa superior da estabilidade da pirofilita). O Grupo Martinópole foi redefinido como uma unidade oriunda de rochas vulcanoclásticas, com contribuições vulcânicas locais (Companhia Austral 1980, Soares 1988, entre outros autores) e elásticas, permanecendo, entretanto, com duas unidades: Formação Covão (basal) e Formação Santa Terezinha. O Grupo São José consiste em uma unidade de posição estratigráfica incerta, com relação ao Grupo Martinópole, e a sua definição na geologia do gráben é ainda confusa. Esse último grupo, por sua vez, é composto de metapelitos e metapsefitos. Os Metassedimentos de Casinha são constituídos por diamictito, com arcabouço formado por seixos pré-foliados das rochas sotopostas (desse modo não é afetado pela fase Dn). Essa unidade evidencia uma forte correlação com a Formação Olho d'Agua do Caboclo, do Grupo Ubajara (de Hackspacher et al. 1988). O Grupo Jaibaras preenche pequenos semigrábens e foi depositado em cunhas elásticas molássicas, caracterizadas por paraconglomerados brechóides proximais da Formação Massapé, além de elásticos finos da Formação Pacujá, ambos de idades tardi-brasilianas. Todas as seqüências são afetadas por zonas de cisalhamento/falhas com magnitudes, natureza de deformação e idades variadas.

Palavras-chaves: Noroeste do Ceará, Gráben de Martinópole, evolução tectonometamórfica, metamorfismo, estratigrafia, geologia estrutural.

INTRODUÇ̃̃O Estudos de seqüências deposicionais complexas, caracterizadas por contribuições vulcanoclásticas e associadas a ambientes de riftes proterozóicos, ganharam espaço nos últimos anos, principalmente em virtude desses ambientes constituírem alvos da prospecção de metais estratégicos no mundo (Hutchinson 1982, Carson \& Mitchell 1982, Gale 1983, Windley 1986, entre outros). Desse modo o presente trabalho visa contribuir para um conhecimento mais abrangente acerca da geologia do Gráben de Martinópole e de sua evolução geológica na região noroeste do Ceará.

O método de trabalho consistiu em correlacionar as diferentes feições litológicas, estratigráficas e estruturais-metamór- ficas, a partir de interpretações fotogeológicas, estudo de afloramentos, integração de dados no contexto regional e interpretação de um mapa geológico, publicado por Oliveira (1987). Os dados desse relatório principal foram reavaliados e reestudados, sobretudo aqueles referentes à petrogênese das rochas vulcanoclásticas, à evolução tectonometamórfica e às relações estratigráficas entre as unidades.

A área estudada situa-se no extremo noroeste do Estado do Ceará (Fig. 1) e compreende partes dos municípios de Granja e de Uruoca; possui área de $225 \mathrm{~km}^{2}$ e está contida na quadrícula SA-24-Y-C-III-3. O local é acessível pela rodovia BR-222 e, em seguida, pela rodovia estadual CE-122 ou a CE-071, que passam pelo local do mapeamento. 


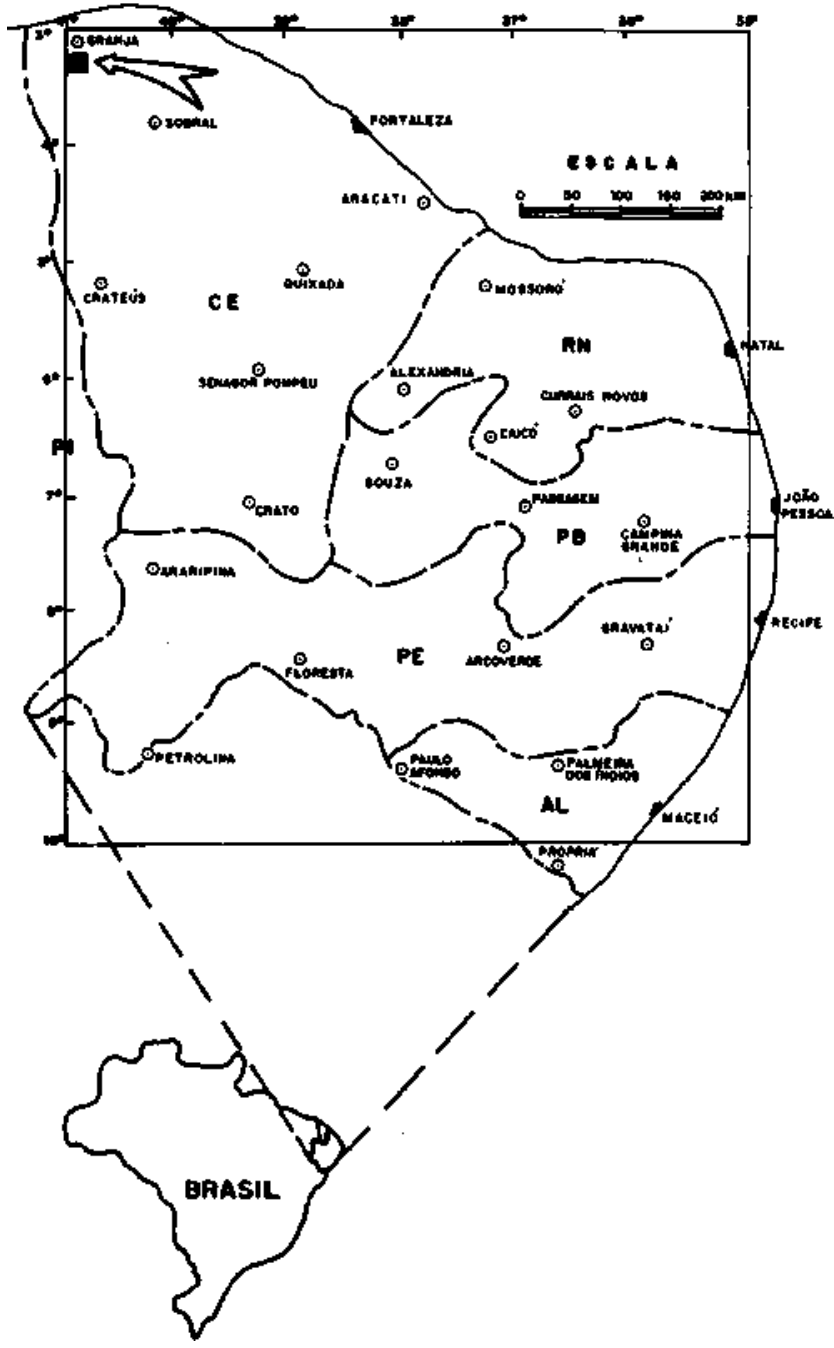

Figura 1 - Mapa de localização da área estudada Figure 1 - Localization map of the study area

ARCABOUÇO GEOLÓGICO REGIONAL A região pesquisada acha-se inserida no contexto da Província Borborema (Almeida et al. 1977), mais precisamente no Sistema de Dobramentos Médio Coreau (Neves 1975) ou no Cinturão de Cisalhamento Noroeste do Ceará (Abreu et al. 1988, Fig. 2). Neste, os altos estruturais representam o embasamento, com idades definidas como, no mínimo, transamazônicas (Neves 1975, Abreu \& Lafon 1991, Gorayeb et al. 1991) ou presumivelmente arqueanas (Sá 1984, Santos \& Neves 1984, Hackspacher et al 1991). Os baixos estruturais compreendem o Gráben de Martinópole, onde Prado et al. (1981) relatam idades "uruaçunas", e Gráben de Ubajara, provavelmente de idade brasiliana (Novais et al. 1979, Hackspacheref«/. 1988). Esses grábens, por sua vez, encontram-se sobrepostos por uma seqüência molássica brasiliana, designada Grupo Jaibaras. Toda a região é marcada por manifestações magmáticas, tais como o granitóide alcalino Mocambo e o Meruoca (Sial et al 1981), os enxames de diques ácidos a noroeste de Sobral, provavelmente mais antigos que os granitos anteriores, e o Vulcanismo Parapui do Gráben Ubajara, com caráter continental (Projeto Radambrasil 1981).

As primeiras referências, acerca das rochas do Gráben de Martinópole, devem-se a Kegel et al. (1958). Costa et al. (1973) foram os primeiros a descrever tipos de rochas, confeccionar um mapa geológico e propor uma estratigrafia informal para a região. No mapeamento geológico desenvolvido pela Companhia Austral (1980) para a Caraíba Metais, diversas rochas vul- cânicas foram descritas, tais como tufos de granulometria grosseira, intermediários e ácidos, até rochas químicas como cherts e calcário. Em adição, constataram-se mineralizações sulfetadas de $\mathrm{Zn}, \mathrm{Cu}$ e $\mathrm{Pb}$, em subsuperfície. Nesse mesmo relatório (Companhia Austral 1980), a forma como se trata a estratigrafia é confusa, visto que os autores não distinguem as rochas do Grupo Jaibaras daquelas do Grupo Martinópole. A primeira estratigrafia para as rochas do Gráben de Martinópole, basicamente com conotação cartográfica e litológica, foi advogada por Prado et al. (1981), individualizando-se da base para o topo como: Formação São Joaquim (quartzitos puros e micáceos com lentes feniferas); Formação Covão (micaxistos com intercalações carbonáticas); Formação Santa Terezinha (filitos e quartzo xistos); e, ainda, uma unidade estratigráfica independente, denominada Grupo São José (cherts e elásticos de baixo grau metamórfico). $\mathrm{O}$ embasamento dessas rochas (em fácies granulito, segundo Gorayeb \& Abreu 1989) foi chamado Complexo Gnáissico-Migmatítico. Em contexto regional, ocorre ainda o Grupo Ubajara (elásticos e carbonates) e as molassas tardi-brasilianas, denominadas Grupo Jaibaras.

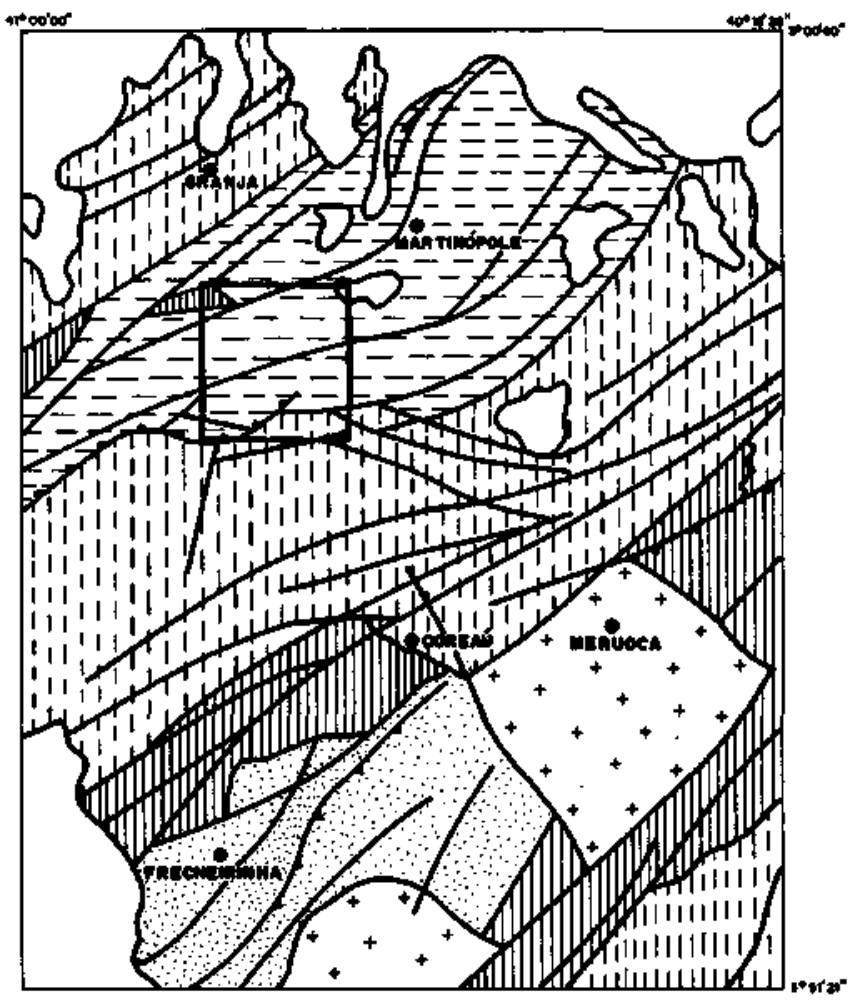

LEOEMA

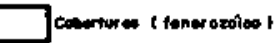

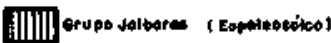
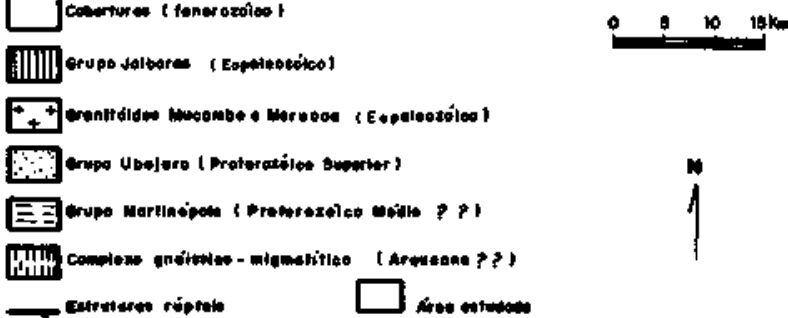

Figura 2 - Mapa geológico regional simplificado do noroeste do Ceará. Notar o forte controle exercido pelas zonas de cisalhamento regionais quando ocorrem as megasseqüências estratigráficas. (Adaptado de Projeto Radambrasil 1981) Figure 2 - Simplified regional geologic map of the Northwestern of Ceará State, showing a strong control by shear zones on the occurrences stratigraphic megasequences. (Adapted from Projeto Radambrasil 1981) 
Uma evolução estrutural complexa é reconhecida para as rochas da região do Gráben de Martinópole, devido ao caráter policíclico de suas deformações. Oliveira et al. (1988) individualizaram duas fases de dobramentos no embasamento (transamazônicas ou mais antigas $\left.D_{n-2} / / / D_{n-1}\right)$. Dn constitui a fase mais importante e penetrativa do Gráben, tendo desenvolvido dobras isoclinais com eixo NW-SE, rotacionado progressivamente para E-W. Nessa fase desenvolveram-se dobras em bainha (nos quartzitos) a isoclinais/fechadas, e o plano evidenciado na mesma varia de uma xistosidade fina a uma foliação milonítica, que representa os planos axiais das dobras mapeáveis. $D_{n+1}$ gerou uma clivagem de crenulação/clivagem ardosiana. A fase $\mathrm{D}_{\mathrm{n}+2}$ denota localizadamente uma clivagem de fraturas, com desenvolvimento de dobras isoclinais a abertas. As zonas de cisalhamento verticais e/ou as falhas, a forte clivagem de crenulação e as dobras angulares (geralmente en chevron) representam a fase $D_{n+3}$. Já na $D_{n+4}$, desenvolveram-se microcisalhamentos, dobras em estágio frágil, ondulações e mesodobras nas molassas brasilianas.

A geologia da região noroeste do Ceará destaca-se por uma forte correlação com o Oeste da África, mais precisamente com a região do Hoggar Ocidental, onde foi reconhecido um Ciclo de Wilson completo, durante a Orogênese Pan-Africana (Black et al. 1979, Caby et al. 1981, entre outros). Com base em dadosde correlação, Sá (1984) especulou que tais feições geotectônicas poderiam continuar no noroeste do Ceará, com possíveis ofiolitos e as zonas de suturas, além de outras feições de zonas de subducção localizando-se sob a Bacia Paleozóica do Maranhão.

GEOLOGIA DA ÁREA Ao se estabelecer o mapeamento geológico-estratigráfico, algumas dificuldades tornaram-se patentes, sobretudo: a. nas fotografias aéreas, uma vez que não existe um controle textural-morfológico para as rochas que compõem a maior parte do Gráben de Martinópole, devido ao forte mascaramento resultante de um solo bastante espesso; b. há fortes evidências de um tectonismo horizontal, associado a zonas de cisalhamento e/ou dobras invertidas mapeáveis, o que confere um caráter alóctone às unidades; c. os contatos litológicos muito comumente são advindos de falhas/cisalhamento; d. a ausência de estruturas primárias caracterizadoras de ambientes assim como de topo e base; e. uma evolução tectonometamórfica polifásica complexa; e, por fim, f. a falta de dados geoquímicos e geocronológicos conclusivos.

Contudo, com base em critérios de discordâncias (estratigráficas e tectonometamórficas) e de relações de inclusão associadas a um suporte petrográfico, foi possível compor um quadro cronolitoestratigráfico, mostrado no quadro 1 , bem como o mapa geológico da figura 3 , os quais serão discutidos a seguir.

Litoestratigrafia COMPLEXO GNÁISSICO-MIGMATÍTICO (de Prado et al. 1981, Quadro 1 e Fig. 3) Representa o embasamento das litologias supracrustais da área e é litologicamente constituído por gnaisses quartzo-feldspáticos bandados, em geral migmatizados. Em alguns locais, exibe estruturas nebulíticas e estromatolíticas; sua mineralogia essencial consiste em plagioclásio, quartzo e biotita/moscovita. Ao microscópio, a rocha exibe uma textura granuloblástica ineqüigranular, às vezes com forte milonitização. Afloramentos do tipo das litologias que compõem o Complexo GnáissicoMigmatítico podem ser observados por toda a região sul da cidade de Granja, ao longo da rodovia CE-071. O caráter de embasamento, na área em pauta, é corroborado pela presença exclusiva da fase $\mathrm{D}_{\mathrm{n}-1}$, o que evidencia uma discordância com relação às rochas sobrepostas.

FORMAÇÃO SÃO JOAQUIM Foi possível reconhecer duas seqüências com uma evolução tectonometamórfica semelhante assim como fortes afinidades em ambientes deposi- cionais no Gráben de Martinópole. Essa Formação foi subdividida em duas unidades informais, denominadas Unidade I e Unidade II (Quadro 1 e Fig. 3), diferindo, portanto, da nomenclatura inicial estabelecida por Prado et al.(1981).

A Unidade I (basal) é constituída por sillimanita-quartzomuscovita xisto, além de plagioclásio-quartzo-biotita xisto com granada; tal Unidade revela ainda níveis subordinados de gnaisses quartzo-feldspáticos com muscovita. Bons afloramentos desses litotipos podem ser observados no leito do Rio Coreau, a oeste da localidade de Campanário. Ao microscópio exibem textura lepidoblástica a granuloblástica fina/média e localmente apresentam um bandamento fino, resultante da alternância de faixas quartzo-feldspáticas e micáceas.

Os litotipos dessa unidade encontram-se muito influenciados por uma componente de cisalhamento, que imprime uma textura milonítica, marcadamente anastomosada. A Unidade I acha-se em contato falhado com o restante das rochas mapeadas, com exceção das rochas da Unidade II, sobre as quais a unidade anterior encontra-se empurrada.

A Unidade II, por sua vez, é composta de muscovita quartzito, cianita-muscovita quartzito, feldspato-mica branca quartzito, com lentes de quartzo-muscovita xisto e cálcio-silicáticas. Em fotografias aéreas, evidencia cristas bem orientadas sobressaindo na topografia regional. Uma seção tipo pode ser observada ao longo da estrada que passa pela localidade de Paula Pessoa. Em geral essa Unidade acha-se empurrada sobre o embasamento e/ou as litologias da Unidade I. Exibe um acamamento bem peculiar, decorrente da alternância de faixas de granulação, cores e composição diferentes, com espessuras que variam de milimétricas a decimétricas. Ao microscópio os quartzitos exibem texturas granuloblásticas finas de caráter mortar", podendo apresentar uma milonitização intensa. As unidades que compõem a Formação São Joaquim desenvolvem uma discordância (discutida adiante) na fase de dobramento principal $(\mathrm{Dn})$, em relação às rochas do Gráben de Martinópole.

Essa associação de xistos grauváquicos com quartzitos é muito comum na evolução sedimentar de seqüências proterozóicas (Condie 1982a, 1982b, Christie-Blick et al. 1988, entre outros) e representa uma progressão normal de faixas desde flysch a plataformas extensas até mares epicontinentais. Apesar das limitações do mapeamento, as características gerais da For-mação São Joaquim sugerem uma deposição em um típico ambiente marinho, podendo a Unidade I ser a porção flysch (dada pelas características texturais e composicionais), enquanto a Unidade II representaria uma plataforma (fato confirmado principalmente pela presença de cálcio-silicáticas). A conformação atual constatada na Unidade II sugere um espessamento, em virtude desta encontra-se cavalgada sobre a Unidade I bem como sobre o Complexo GnáissicoMigmatítico (Oliveira et al. 1988,Petta et al. 1989, Pedreira \& Torquato 1991).

GRUPO MARTINÓPOLE (Quadro 1 e Fig. 3) Tal unidade foi caracterizada como tipicamente oriunda de rochas vulcanoclásticas, diferindo da maneira como foi descrita na formalização de Neves (1975) e Prado et al (1981); no entanto, permanece aqui com a mesma nomenclatura e subdivisão em formações.

A Formação Covão (basal) é constituída por quartzo-pirofilita xisto, quartzo-clorita-mica branca xisto, com pequenas intercalações de muscovita quartzito, mica branca quartzito, quartzitos puros (possíveis metacherts) e ainda clorita filitos, oriundos de tufos de granulometria grosseira, além de talco xistos (?) em alguns locais. Bons afloramentos dessa unidade podem ser encontrados ao longo da rodovia CE-071, na localidade de Alto do Assovio. Observa-se um acamamento planoparalelo milimétrico bastante penetrative nessa unidade. Localmente, observam-se pequenas estratificações cruzadas de baixo ângulo $\left(5 \mathrm{a} 10^{\circ}\right)$, com evidência de topo e base normais. 
Quadro 1 - Coluna cronolitoestratigráfica da área em estudo. A relação estratigráfica entre o Grupo Martinópole e o São José ainda não foi estabelecida (ver texto). Notar o posicionamento dos eventos tectonometamórficos na coluna. Acompanhar os símbolos das unidades no mapa geológico da figura 3

Chart 1 - Chronolithostratigraphic column of the area. The stratigraphic relationship between the Martinópole Group and the São José Group has not been established yet (see text). Note the tectonometamorphic events position in the column. The unit symbols are in the geologic map of figure 3

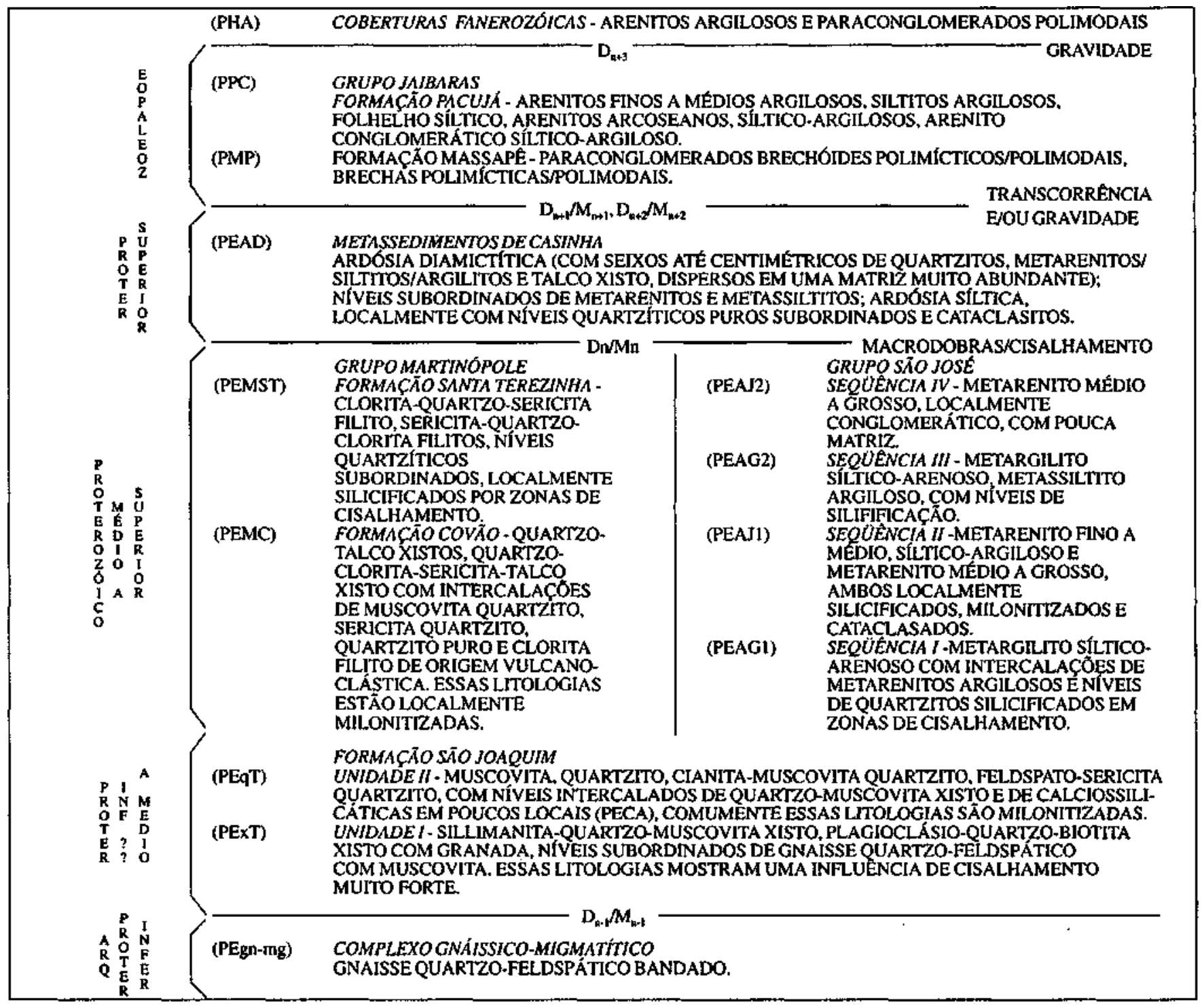

A Formação Santa Terezinha é composta de clorita-quartzomica branca filitos, os quais variam sua percentagem mineral de local para local. De modo subordinado, ocorrem quartzitos puros (metacherts). Essa unidade aflora no extremo nordeste da área mapeada, marcadamente na região da localidade de Bracutiara.

A relação estratigráfica entre as formações descritas acima, como referida por Prado et al. (1981), é também constatada pelo mapeamento em pauta, e pode ser observada na porção norte-nordeste da área. Nesse local, os filitos da Formação Santa Terezinha mergulham sobre os xistos da Formação Covão (Fig. 3). Vale salientar que, no presente trabalho, não foi possível estabelecer um vínculo estratigráfico entre o Grupo Martinópole e o São José, uma vez que estes encontram-se em contato por meio de falhamentos verticais. "Desconfia-se", entretanto, que o Grupo São José esteja metamorfizado em níveis crustais superiores, devido às associações paragenéticas de illita/caulinita(?)/quartzo/pirofilita (fácies prehnita/ pumpellyíta) observadas, enquanto o Grupo Martinópole atingiu normalmente a isógrada da clorita.
As litologias do Grupo Martinópole, como um todo, resumem características de origem em vulcanoclastitos, especificamente em tufos a cinzas vulcânicas de afinidade félsica. A textura, os fabrics e as estruturas sedimentares mostradas para os litotipos do Grupo Martinópole sugerem uma deposição em ambiente continental, provavelmente subaéreo (segundo comparações com dados de Lajoie 1980 e Fisher \& Schmincke 1984). Entretanto é necessário considerar as contribuições de outros ambientes, sobretudo o lacustre.

GRUPO SÃO JOSÉ Quadro 1 e Fig. 3) Em virtude da difícil definição sob o ponto de vista de mapeamento dessa unidade e de sua forte semelhança com litologias do Grupo Martinópole, tal como descrito por Prado et al. (1981), foram denominadas aqui Grupo São José, as rochas metassiliciclásticas de "baixíssimo grau metamórfico" e que localmente denotam estruturas primárias preservadas. A relação estratigráfica desse grupo na área é incerta (como comentado anteriormente) e, além disso, uma definição adequada de ambientes deposicionais é ainda problemática. Afloramentos dessas 


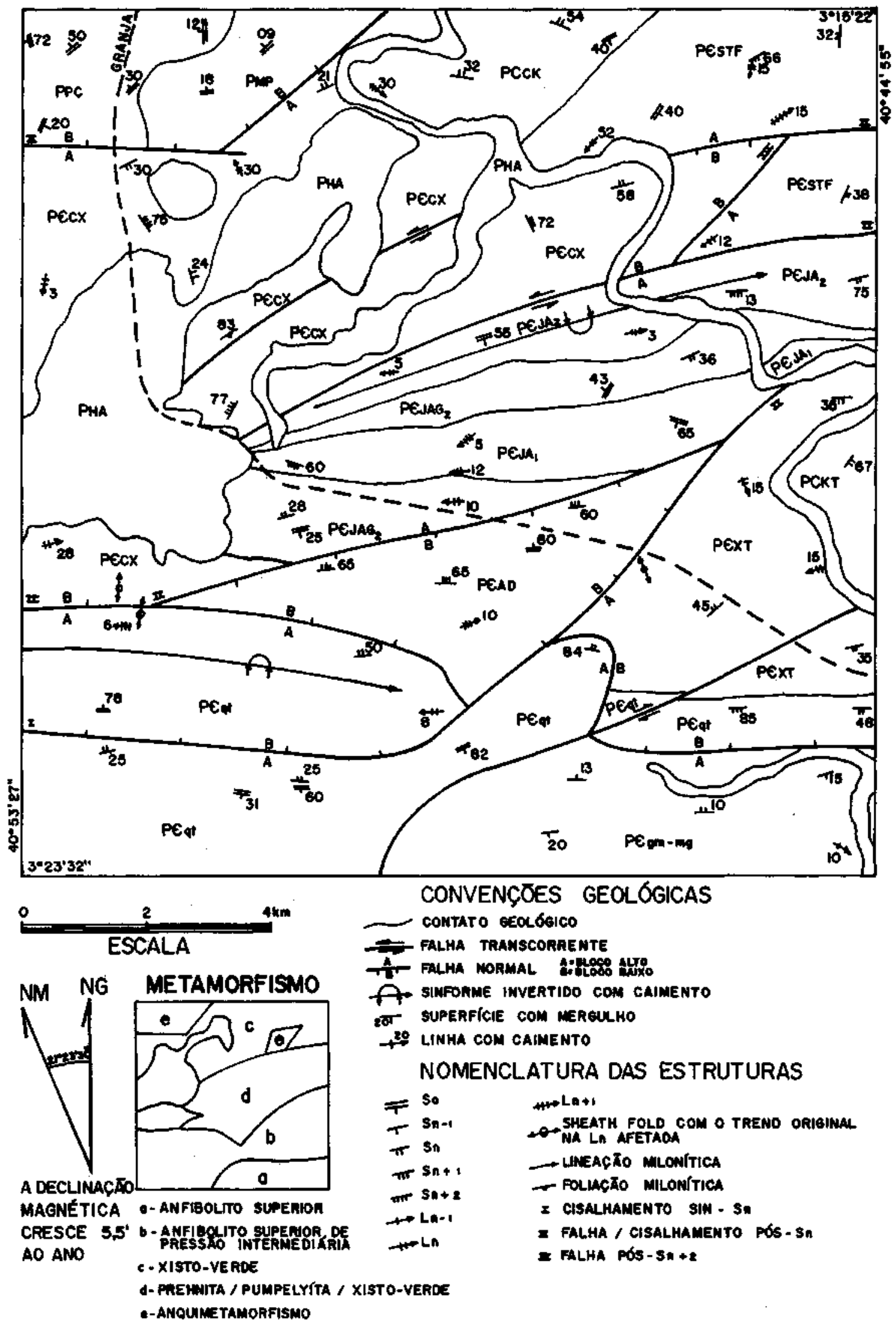

Figura 3 - Mapa geológico da área. Acham-se plotadas as atitudes das mesodobras e também é mostrada a faixa de ocorrência das fácies metamórficas (principalmente na fase Mn), quase sempre coincidente com os contatos entre as unidades estratigráficas (ver texto). Os simbolos das unidades encontram-se dispostos na coluna estratigráfica do quadrol

Figure 3 - Geologic map of the study area, with location of measured mesofolds attitudes and the distribution of metamorphic facies, whose boundaries are, in most cases, the same as those of stratigraphic units (see text). The unit symbols are in table 1 
rochas podem ser vistos na localidade de Tapera, na rodovia CE-071.

Por toda a extensão do Gráben de Martinópole, são comuns ocorrências de seqüências alternantes de metarenitos com metargilitos (características típicas do Grupo São José). Com efeito, na área mapeada essa unidade foi subdividida em quatro seqüências sedimentares informais, a saber, da base para o topo (ver Fig. 3): Seqüência I, um pacote monótono de metargilitos, com delgadas intercalações de metarenitos; Seqüência II, um espesso pacote de metarenitos, finos a grossos, com níveis de metargilitos intercalados; Seqüência III, compreendida basicamente por metargilitos; e, por fim, Seqüência IV, formada por metarenitos finos a grossos, com contribuições conglomeráticas locais. Todas as seqüências referidas encontram-se dobradas de modo invertido e localmente apresentam extrema silicificação, devido a cisalhamentos.

METASSEDIMENTOS DE CASINHA (Quadro 1 e Fig. 3) Essa unidade corresponde a uma ardósia diamictítica (com fragmentos decimétricos a centimétricos de quartzitos da Formação São Joaquim, xistos da Formação Covão e metassedimentos do Grupo São José, dispersos em uma abundante matriz areno-argilosa) e ainda a níveis subordinados de metarenitos/argilitos.

Até o presente mapeamento, os Metassedimentos de Casinha haviam sido mapeados como constituindo a Formação Covão (Grupo Martinópole), sendo este, talvez, um dos principais problemas geocronológicos da área, ou seja, rochas de idades muito diferentes, consideradas como compatíveis estratigraficamente. Seu posicionamento estratigráfico acima do Grupo Martinópole e do São José deve-se ao fato da mesma conter fragmentos de rochas das referidas unidades. Outro forte argumento refere-se a tais fragmentos encontrarem-se previamente foliados, denotando uma discordância entre essa unidade e as litologias que constituem os fragmentos, como esquematizado na figura 4 . Boas exposições dessas litologias podem ser vistas em cortes de estrada na rodovia CE-071, a leste da localidade de Tapera.

Pelas características macrotexturais (ardósias avermelhadas com leitos descontínuos de metarenitos/siltitos), composicio- nais (desenvolve a mesma mineralogia e, portanto, o mesmo grau metamórfico) e estruturais (desenvolve apenas duas estruturas contínuas, sendo a principal uma clivagem ardosiana, e a segunda, uma clivagem de crenulação penetrativa em alto ângulo com a principal), os Metassedimentos de Casinha mostram-se fortemente correlacionáveis com as ardósias descritas na Formação Olho d'Água do Caboclo (Hackspacher et al. 1988), estratigrafícamente acima do Grupo Ubajara. A objeção que se faz é com referência às rochas descritas pelos autores não possuírem a fácies diamictítica; contudo isso provavelmente reflete um regime de sedimentação local.

GRUPO JAIBARAS (de Winge 1967, Quadro 1 e Fig. 3) Preenche, no Gráben de Martinópole, pequenos pull-aparts, em regiões onde os cisalhamentos foram muito ativos, efetivados em grandes ramos secundários que delimitam essas bacias. No mapeamento, esse Grupo perfaz dois pequenos grábens: o de Jaguarapi, situado no extremo noroeste e o outro na porção centro-nordeste. $\mathrm{O}$ primeiro acha-se preenchido pelos sedimentos da Formação Massapé e da Pacujá (topo), sendo a Massapé a única constatada no gráben centronordeste.

A Formação Massapé é constituída por paraconglomerados brechóides polimícticos/polimodais, de aparência bastante desorganizada; há diferenças na composição do arcabouço das duas ocorrências. Na parte noroeste, aparecem matacões de mais de $1 \mathrm{~m}$ de diâmetro, sobretudo possuindo a composição do embasamento Complexo Gnáissico-Migmatítico. Na ocorrência da porção nordeste, a granulometria dificilmente chega a seixos com composição apenas do Grupo Martinópole. Essa unidade como um todo caracteriza uma associação em cunhas elásticas de molassas brasilianas, depositadas em leques aluviais.

A Formação Pacujá é formada por arenitos finos/médios a argilosos, grauvacas, além de arenitos conglomeráticos arcoseanos. Alcançou anquimetamorfismo, tendo se depositado em ambientes lacustres, nas partes mais distais do Gráben de Martinópole. Boas exposições do Grupo Jaibaras podem ser visualizadas ao longo do Riacho Sairi, próximo à localidade de Morada Nova.
(A)

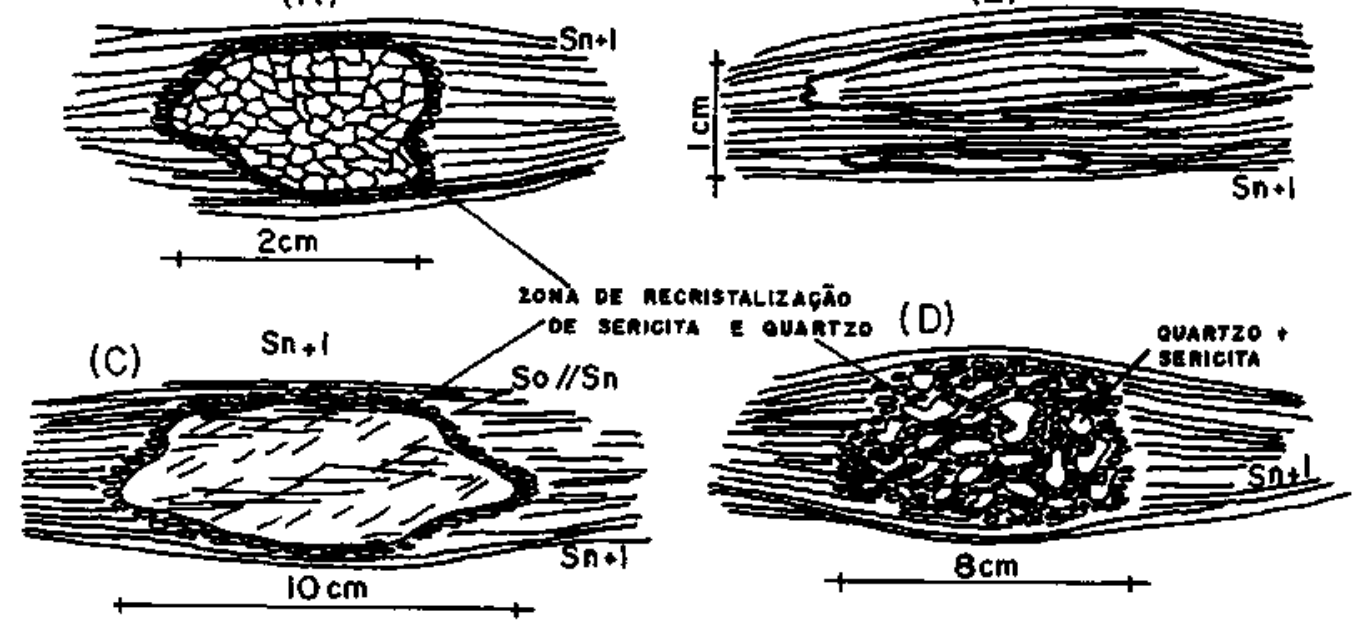

Figura 4 - Desenho esquemático dos diversos tipos de fragmentos de rochas presentes nos Metassedimentos de Casinha: $\boldsymbol{A}$. quartzito, com recristalização de novos grãos nas bordas do fragmento; $\boldsymbol{B}$. xisto da Formação Covão, intensamente estirado, segundo a foliação principal $S_{n+l} ;$ C. Metargilito do Gmpo São José, sobressaindo o So e uma foliação prévia (Sn) subparalelos; D. Metarenito argiloso do Grupo São José com recristalização de quartzo e serícita nas bordas bem como no interior do fragmento. A foliação $S_{n+1}$ (clivagem ardosiana) acha-se impressa em todos os fragmentos

Figure 4 - Schematic draw of the several kinds of rock fragments from Metassedimentos de Casinha: A. quartzite, with nucleation of new grains along fragment boundaries; B. Covão Formation schist, intensively stretched, along the main foliation $\mathrm{S}_{\mathrm{n}+1}$; C. São José Group metaclaystone, showing the So and a previous foliation $(\mathrm{Sn})$, which are 0 subparalell; D. argillaceous metasandstone of São José Group with quartz and sericite recrystallization along the edge and the internal part of the fragment. The foliation $\mathrm{S}_{\mathrm{n}+1}$ (slate cleavage) was impressed in all studied fragments 
Localmente, essa unidade acha-se pouco deformada, o que reforça sua deposição tardibrasiliana, estratigraficamente acima dos Metassedimentos de Casinha. Novais et al. (1979) relataram datações $\mathrm{Rb} / \mathrm{Sr}$ em rocha total e argilas, fornecendo uma isócrona verdadeira em folhelhos da Formação Pacujá, do Gráben de Jaguarapi (Fig. 5). Essa isócrona revelou uma idade de $551 \pm 20 \mathrm{Ma}$, compatível com as estabelecidas para o final do Ciclo Brasiliano.

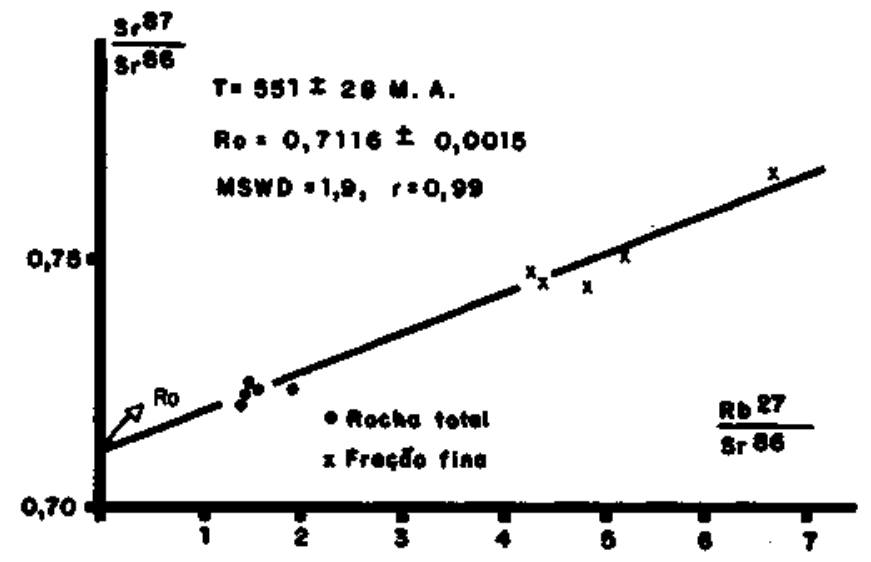

Figura 5-Isócrona verdadeira, $\mathrm{Rb} / \mathrm{Sr}$ (rocha total e fração fina) em folhelhos silticos da Formação Pacujá (Grupo Jaibaras), no pequeno Gráben de Jaguarapi. Compilado de Novais et al. (1979)

Figure $5-\mathrm{Rb} / \mathrm{Sr}$ isochronic dating (whole rock and fine fraction) for mudstones of Pacujá Formation from the small Jaguarapi Graben. (After Novais et al. 1979)

Evolução tectonometamórfica Em termos estruturais, a área apresenta-se muito complexa, devido a um caráter policíclico de suas deformações, dificultando, consideravelmente, sua interpretação. A metodologia de análise estrutural foi baseada em Sá \& Hackspacher (1982) e em Mosher \& Helper (1988). A definição e a classificação das fácies metamórficas, por sua vez, foram fundamentadas em Miyashiro (1973). Especificamente para as rochas de baixo grau metamórfico, foi difícil a determinação exata ao microscópio dos minerais constituintes, desse modo vários deles, principalmente os placosos, são tratados como micas brancas. Cinco fases de estruturação com quatro metamorfismos associado foram distinguidas, sendo algumas delas progressivas em um mesmo evento deformativo. A fase regional mais penetrativa foi convencionda como Dn/Mn, de acordo com Oliveira et al. (1988).

As associações minerais, cristalizadas por fases metamórfícas para as rochas do Gráben de Martinópole e determinadas nos principais litoambientes, podem ser acompanhadas no quadro 2. Já as feições estruturais mais características dessas fases podem ser acompanhadas no quadro 3 .

FASE (n-1) Presente exclusivamente no embasamento Complexo Gnáissico-Migmatítico.

Estnituras/metamorfismo Acha-se representado por um bandamento grosseiro de trend $\mathrm{EW}$, em geral com mergulhos altos; $\mathrm{L}_{\mathrm{n}-1}$, é uma lineação mineral subhorizontal. A associação mineral cristalizada nessa fase é composta principalmente de: plagioclásio (An 21\%)/quartzo/biotita/feldspato potássico. Com base nas características do plano $\mathrm{S}_{\mathrm{n}-1}$, um bandamento quartzo-feldspático grosseiro, bem como na sua composição mineral, é possível sugerir que o feldspato potássico tenha se formado por reações de anatexia, em temperaturas perto do solidus do granito, sem envolver-se na formação de silicatos de
Quadro 2 - Principais associações minerais classificadas por fases metamórficas e relacionadas com seus "litoambientes". A linha tracejada corresponde a um posicionamento incerto. Legenda: A.S. anfibolito superior; P.P. prehnita-pumpellyita; $X . V$. xisto-verde; $\boldsymbol{X . V . I , ~ x i s t o - v e r d e ~ i n f e r i o r ; ~} \boldsymbol{X . V . S . ~ x i s t o - v e r d e ~}$ superior

Chart 2 - The main mineral paragenesis classified by metamorphic phases and showing their relations with the "lithoenviroments". The dashed line means an uncertain position. Legend: A.S. upper amphibolite facies; P.P. prehnitepumpellyite facies; X.V.I, lower green schist facies; X.V.S. upper green schist facies

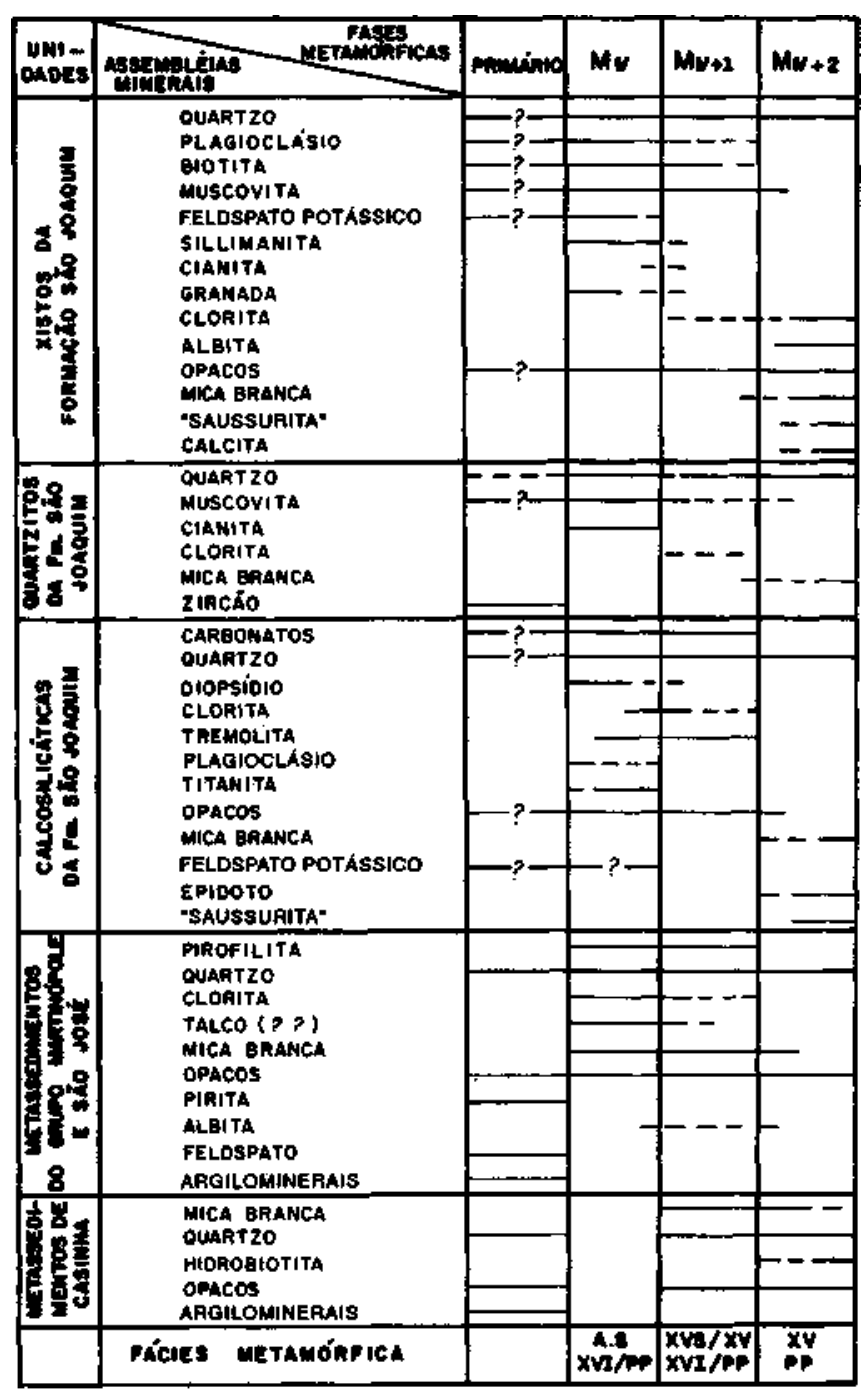

alumínio com $\mathrm{PH}_{2} \mathrm{O}$ de aproximadamente 5 kbar e $\mathrm{T}=680^{\circ} \mathrm{C}$ (semelhante ao discutido por Winkler 1976). Desse modo, o pico de metamorfismo impresso por $\mathrm{M}_{\mathrm{n}-1}$, encontra-se em fácies anfibolito superior (passagem a fácies granulito), na isógrada do feldspato potássico.

FASE (n) Trata-se da fase mais penetrativa e importante de toda a região em estudo.

Estruturas No embasamento, nota-se o desenvolvimento de dobras isoclinais de caráter originalmente recumbente, às vezes com transposição. Nos xistos da Formação São Joaquim, ocorrem dobras isoclinais a fechadas, desde horizontais até reclinadas, enquanto nos quartzitos da mesma Formação aparecem dobras em bainha (Fig. 6), onde há uma comprovada influência de empurrão associada a cisalhamento. Essas dobras são provavelmente reflexos de acomodação local de material 
Quadro 3 - Principais feições estruturais definidas por fases tectônicas

Chart 3 - The major structural features and their corresponding tectonic phases

\begin{tabular}{|c|c|c|c|c|c|c|}
\hline PASE & $\begin{array}{l}\text { OOMLTAK } \\
\text { DAs borRAs }\end{array}$ & 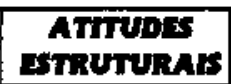 & 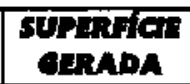 & $\begin{array}{l}\text { SUPARFE } \\
\text { DOBRADA }\end{array}$ & $\begin{array}{l}\text { Platix } \\
\text { Miramenfia }\end{array}$ & onstnuacts \\
\hline$(n-1)$ & 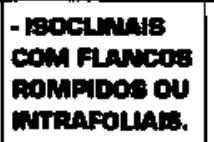 & 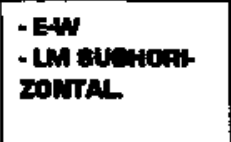 & $\begin{array}{l}\text { anuar } \\
\text { mento enos. } \\
\text { seimo. }\end{array}$ & & 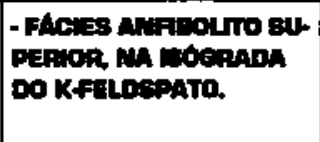 & 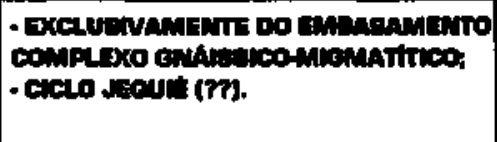 \\
\hline (n) & 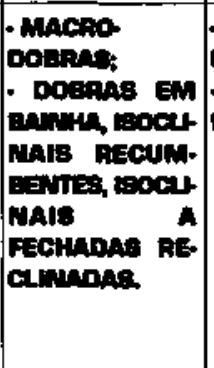 & 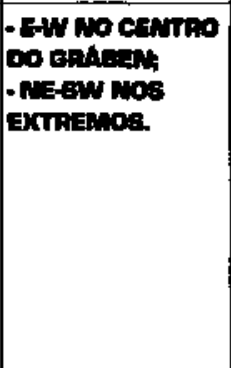 & 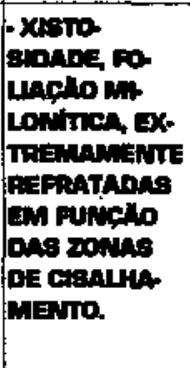 & 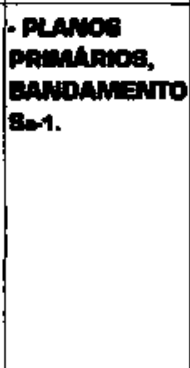 & 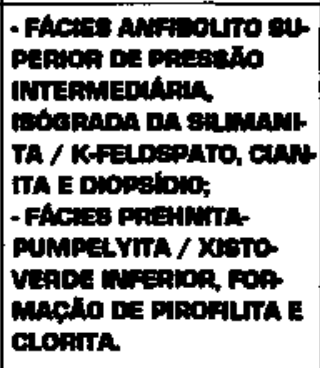 & 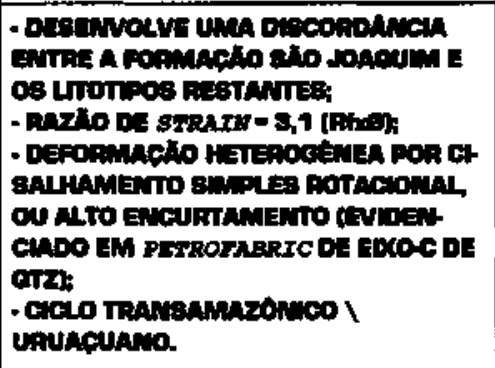 \\
\hline$(n+1)$ & 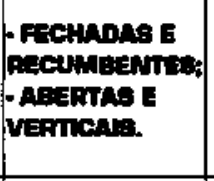 & 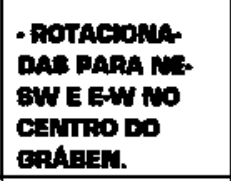 & 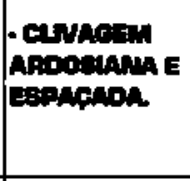 & $\begin{array}{l}-80 / / 8 E \\
\text { Bavpat } \\
\text { MENTo sm. }\end{array}$ & 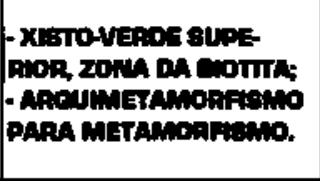 & 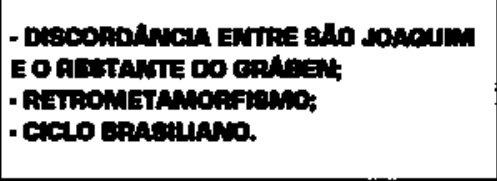 \\
\hline$(n+2)$ & $\begin{array}{l}\text { - Dorinas } \\
\text { cutruron }\end{array}$ & - REGAY E EW. & 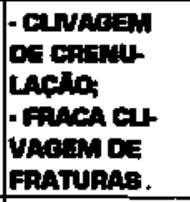 & $-e_{0} / / \sin _{0}=1$. & 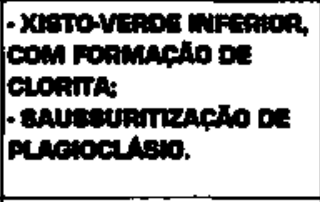 & 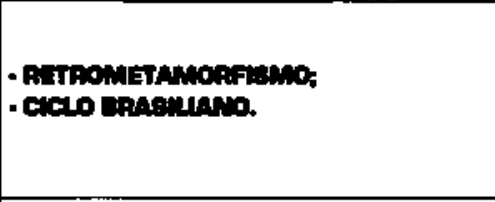 \\
\hline$(n+3)$ & 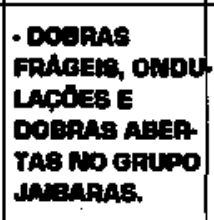 & - Rosen. & $\begin{array}{l}\text { zomas cath } \\
\text { cunagas. }\end{array}$ & 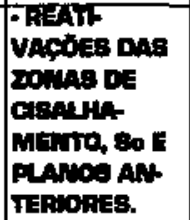 & & 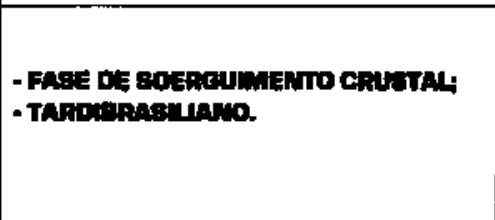 \\
\hline
\end{tabular}

(Hackspacher 1989) ocorrida durante a instalação das macroestruturas tipo duplex (Oliveira et al. 1988, Petta et al. 1989). A geração das macrodobras mapeáveis, invertidas e recumbentes, que ocorrem por toda a faixa de afloramentos do Grupo Martinópole e do São José, é creditada à fase (n), em virtude dessas dobras possuírem a foliação Sn como plano-axial.

Os planos contínuos desenvolvidos nessa fase variam de uma xistosidade/foliação milonítica a uma clivagem ardosiana/ xistosidade muito fina. Mostram direção preferencial NE-SW, com variações em todos os quadrantes (resultantes provavelmente da refração dos planos em regiões de extremo cisalhamento; Abreu et al. 1988), conforme ilustrado na figura 7. Em geral esses planos denotam mergulhos suaves a moderados, tanto para SE como para NW. A lineação Ln é dominantemente mineral, todavia, em locais isolados, verifica-se o estiramento de grãos de quartzo, feldspato, rods de quartzo assim como franjas de pressão (ao microscópio), evidenciando um trend EW, com mergulhos suaves para oeste.

Em alguns locais da área estudada (onde as fases subseqüentes atuaram fracamente), foi possível calcular a razão de strain e estudar os mecanismos de deformação atuantes em escala de cristal, durante a instalação de Dn.

Nos metargilitos da Seqüência I do Grupo São José, ocorrem porfiroclastos de pirita, idiomórficos, medindo até mais de $2 \mathrm{~mm}$ e apresentando contatos bem definidos, com desenvolvimento de franjas de pressão (oriundas de quartzes fibrosos do tipo flaser lenticular). Esses porfiroclastos, em sua grande maioria, encontram-se subparalelos à foliação principal $\mathrm{Sn}$. Com base nesses porfiroclastos, foi possível calcular a razão do strain (Rs) pelo método descrito por Ramsay \& Huber (1983). A média de Rs encontrada foi de 3,1 , com rotações de 5 a $10^{\circ}$ (Fig. 8). Esse valor é considerado bastante coerente, uma vez que indica uma profundidade crustal relativamente rasa, em concordância com o metamorfismo de baixas temperaturas e pressão dessa unidade estratigráfica.

Estudos de petrofabric, em eixo c de quartzo, foram efetuados em vários locais do cisalhamento gerado durante os empurrões, nos quartzitos da Formação São Joaquim. O quartzo estudado foi em grande parte do tipo flaser, apresentando pouca extinção ondulatória e geralmente evidenciando processos de recuperação bem como recristalização de subgrãos em suas bordas. As guirlandas de eixo c (Fig. 9) revelam uma simetria monoclínica e pertencem ao tipo faixa máxima". De acordo com Lister \& Hobbs (1979), esse padrão de guirlanda indica um mecanismo de deformação decorrente de cisalhamento simples, com deslizamentos intracristalinos, essencialmente basais. A deformação atuante no local foi heterogênea, rotacional (não-coaxial) e de alto encurtamento, típica de regiões crustais mais profundas (thick-skinned tectonics, de Coward 1983).

Metamorfismo Nessa fase pode ser dividido em dois pulsos. O primeiro acha-se representado nas rochas da Formação São Joaquim, com metamorfismo de alto grau de pressões intermediárias. Já o segundo é evidenciado nas rochas de baixo grau metamórfico, presentes no restante do Gráben de Martinópole. Nos xistos da Formação São Joaquim, houve cristalização de sillimanita, quartzo, granada (almandina), biotita, mus- 


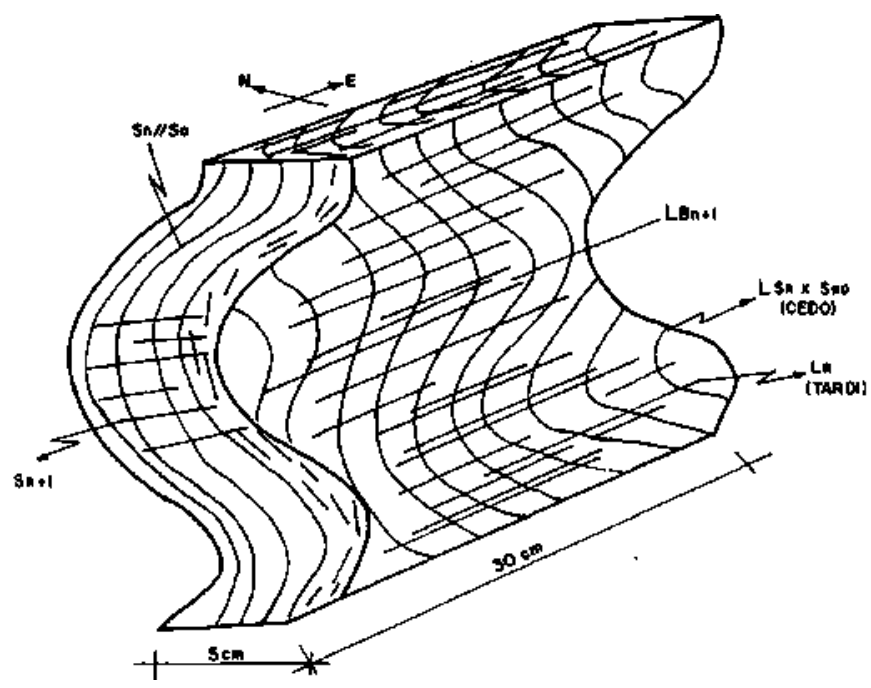

Figura 6-Desenho esquemáíico da dobra em bainha da fase Dn, nos quartzitos da Unidade II da Formação São Joaquim (ver texto). Notar a relação dessa dobra com outras posteriores. Norte da localidade de Paula Pessoa. (Adaptado de Oliveira et al. 1988)

Figure 6 - Schematic draw of the Dn sheathfold in Unit II, in quartzites of São Joaquim Formation (see text). Note the relationship between this fold and the pos-Dn folds. Northern of Paula Pessoa locality. (Adapted from Oliveira et al. 1988)

covita, plagioclásio (An 19\%), feldspato potássico e cianita (?). A principal reação caracterizadora do metamorfismo nessa fase é dada por:

muscovita + quartzo $\leftrightarrows$ feldspato potássico + sillimanita $+\mathrm{H}_{2} \mathrm{O}$.
A reação foi investigada por vários autores. No entanto foi Day (1973 apud Mueller \& Saxena 1977) quem obteve os valores de temperatura e pressão mais altos, como pode ser constatado na isógrada da figura 10 . Essa reação pode ser observada em alguns filmes de muscovita que são encontrados inclusos em feldspato potássico, enquanto a cianita (tarditectônica) provavelmente substitui a sillimanita por ocasião de um aumento de pressão no final da fase metamórfica (caso da rocha estudada). Essa isógrada (sillimanita/ feldspato potássico) representa a passagem do grau médio para o forte de Winkler (1976), estando na porção superior da faties anfíbolito de Miyashiro (1973), para pressão baixa.

O principal mineral metamórfico, verificado nos quartzitos São Joaquim, é o silicato de alumínio do tipo cianita, o qual caracteriza, junto com as ocorrências comuns (nos xistos) de associações da almandina/sillimanita (sem se desestabilizar para cordierita, como discutido por Holdaway \& Lee 1977 e Turner 1987), um metamorfismo em pressão intermediária (Miyashiro 1973), como constatado na figura 10.

As cálcio-silicáticas exibem, nessa fase, as associações paragenéticas de quartzo/diopsídio/feldspato potássico/carbonatos/ tremolita (cedo-tectônica, às vezes inclusa em diopsídio)/opacos, que, por si só, denotam temperaturas que variam de 620 a $700^{\circ} \mathrm{C}$, dependendo da fração molar de $\mathrm{CO}_{2}$ (esta, em pressões intermediárias, chega a 0,7, de acordo com estudos de Jansen et al. 1978). Em geral, a primeira aparição do piroxênio diopsídico ocorre através da seguinte reação (de Metz \& Winkler 1964, apud Miyashiro 1973).

tremolita +3 calcita +2 quartzo $\leftrightarrows 5$ diopsídio $+3 \mathrm{CO}+2 \mathrm{H}_{2} \mathrm{O}$

Essa reação depende do $\mathrm{Xco}_{2}$ escolhido (no caso de metamorfismo regional, o $\mathrm{Xco}_{2}$ da fase fluida constitui o $\mathrm{Xco}_{2}$ da reação). Contudo, se a rocha encontra-se associada a fenômenos envolvendo hidrotermalismo (no caso estudado, devido ao
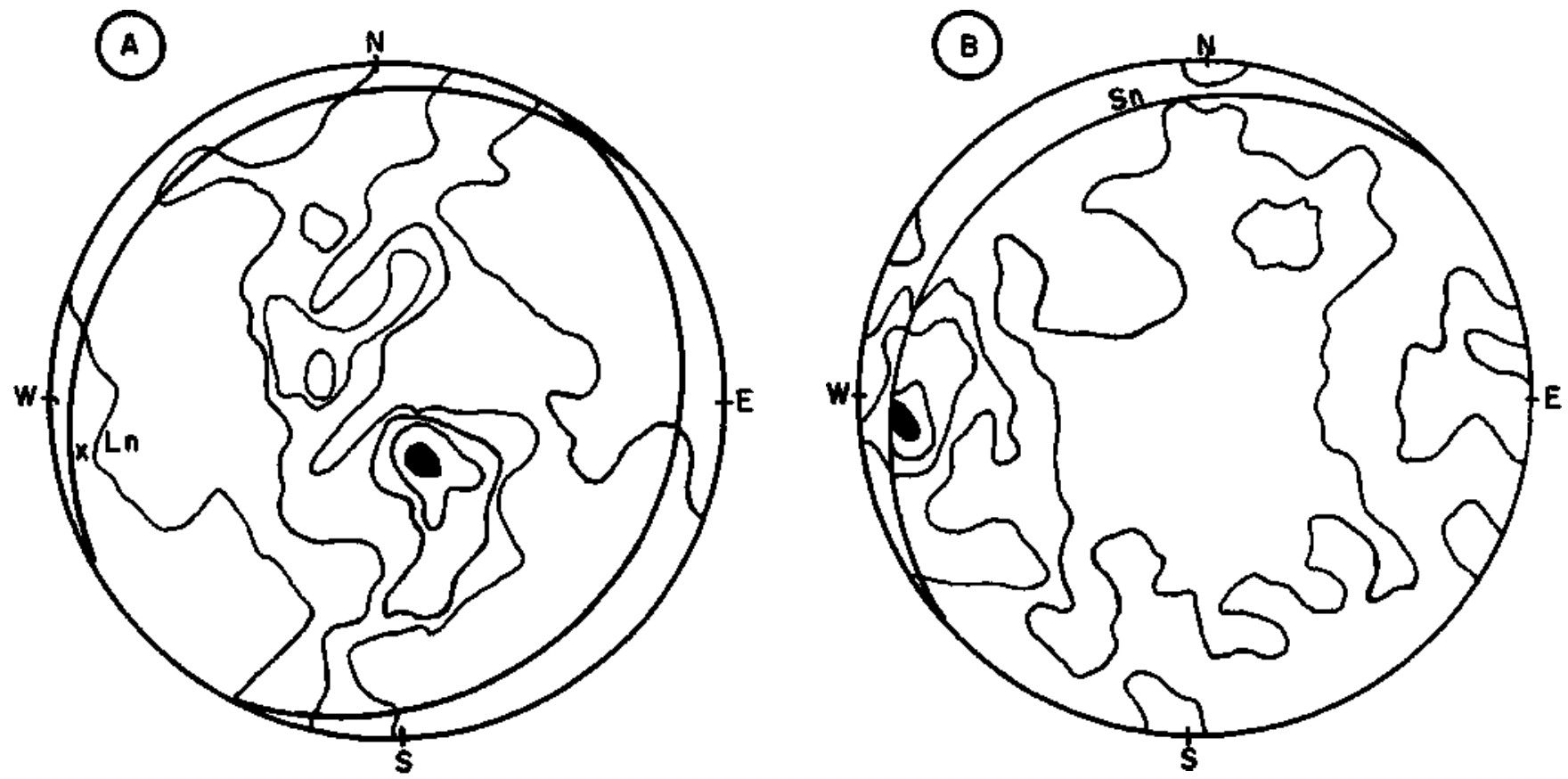

Figura 7 - Estereogramas com as atitudes das principais feições estruturais contínuas de Dn (ver texto): (A)foliação Sn, contornos de 0,52345\%; (B) lineação Ln, contornos de 0,525912\%. Rede de Schmidt, calota inferior, 1\%de área

Figure 7 - Stereogram showing the main continuous Dn structural features (see text): (A) Sn foliation, 0,52345\%; (B) Ln lineation.0,525912\%; Schmidt net, lower hemisphere, area $1 \%$ 
intenso cisalhamento), o $\mathrm{Xco}_{2}$ é mais baixo, implicando um rebaixamento das condições de pressão e temperatura. $\mathrm{O}$ comportamento em diagrama de P-T da isógrada da reação (2) pode ser observado na figura 10. Ainda para Jansen et al (1978), o diopsídio pode ocorrer também pela eliminação direta de dolomita em presença de quartzo.

Nessa mesma fase, o Grupo São José revela texturas primárias muito bem preservadas, sem o desenvolvimento de minerais caracterizadores de fácies metamórficas de baixo grau, indicando, assim, que esse grupo sofreu temperaturas abaixo de $300^{\circ} \mathrm{C}$ (comparação com estudos desenvolvidos por Frey 1970, 1987).

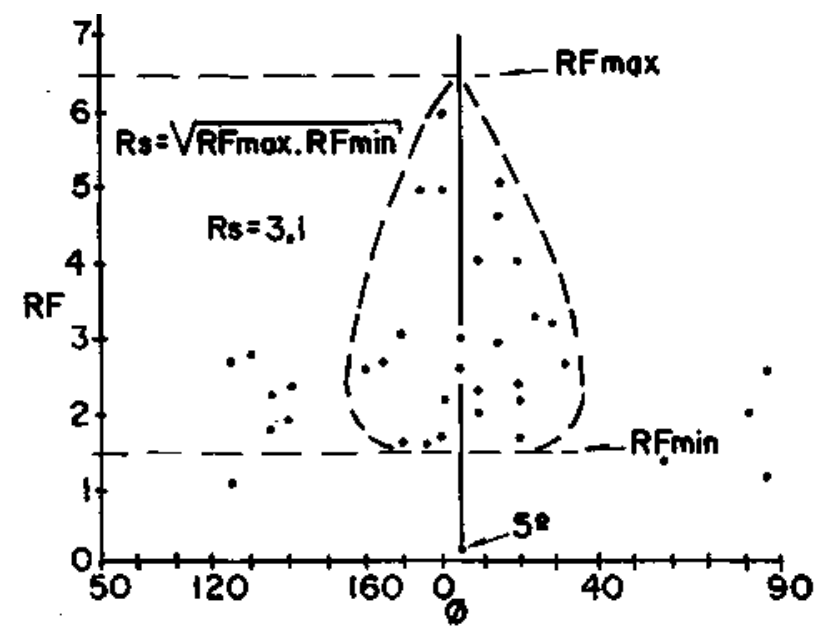

Figura 8 - Quantificação da razão de strain na fase Dn, em cristais de pirita com franjas de pressão, pelo método Rf x phi (Ramsay 1967, apud Ramsay \& Huber 1983), nos metargilitos do Grupo São José. Localidade de Tapera

Figure 8 - Strain ratio quantification on Dn phase, determined in pyrite pressure fringes by the Rf x phi method (Ramsay 1967, apud Ramsay \& Huber 1983). São José Group metamudstone. Tapera locality

Nas rochas do Grupo Martinópole, houve a cristalização de clorita, quartzo e micas brancas, provavelmente pirofilita e/ou paragonita e/ou margarita, pois são muito difíceis de identificar ao microscópio, como comentado anteriormente.

Em rochas de fácies metamórficas de grau muito baixo, a clorita pode ser formada em conjunto com a mica branca, segundo a reação (3), proposta por Frey (1970):

illita/montmorillonita misturadas $\leftrightarrows$ clorita $(\mathrm{Al})+$ mica branca + + quartzo $+\mathrm{H}_{2} \mathrm{O}$

Já, Winkler (1976) considera que clorita alguma persiste acima do metamorfismo de grau médio junto com micas brancas, sendo este um indicador seguro de que a rocha ainda não se encontra em fácies xisto-verde; por outro lado, tal associação é encontrada desde o grau incipiente. Segundo Frey (1987), a associação de clorita com pirofilita restringe sobremaneira o campo da estabilidade $P \quad x \quad T$ de metamorfismo,toda via ainda constitui um assunto a ser estudado,com relação ao metamorfismo de baixo grau.

As principais reações que dão origem às micas brancas são vistas abaixo. Essas reações começam a acontecer ainda em "profundidades bureais".

caulinita +2 quartzo $\leftrightarrows$ pirofilita $+\mathrm{H}_{2} \mathrm{O}$

caulinita + albita $\leftrightarrows$ pirofilita/paragonita + mica branca $++2 \mathrm{H}_{2} \mathrm{O}$

2montmorillonita $\leftrightarrows$ pirofilita +2 mica branca
A reação (4) foi proposta por Thompson (1970, apud Miyashiro 1973) e investigada por Juster (1987); indica condições de pressão de 2 a 3 kbar e temperatura de 225 a $275^{\circ} \mathrm{C}$ (ver Fig. 10). A reação (5) evidencia temperaturas mais elevadas que a anterior e foi averiguada por Hyndman (1972), enquanto a reação (6), por fim, revela temperaturas e pressões ainda superiores às outras duas reações, tendo sido investigada por Velde (1969, apud Hyndman 1972).

De um modo geral, os minerais formados pelas reações acima prosseguem estáveis até a fácies xisto-verde superior. A pirofilita é estável até aproximadamente $525^{\circ} \mathrm{C}$, em pressões de 7 kbar, segundo Althaus (1966, apud Mueller \& Saxena 1977), ou até $410 \pm 15^{\circ} \mathrm{C}$, em pressões de $2 \mathrm{kbar}$, de acordo com Kerreck (1968, citado por esses mesmos autores), quando então ela se desestabiliza para formar silicatos de alumínio. Entretanto, em condições experimentais, nas quais a pressão de água pode ser comparada com a litostática (na natureza esperase que a atividade da água seja bem menor), a presença de pirofilita indica temperaturas entre: 300 a $380^{\circ} \mathrm{C}$ para $2 \mathrm{kbar}$, 310 a $440^{\circ} \mathrm{C}$ para $5 \mathrm{kbar}$ e 350 a $420^{\circ} \mathrm{C}$ para $10 \mathrm{kbar}$ (Frey 1987). Já o limite superior da estabilidade da paragonita, coexistindo com o de quartzo, é um pouco acima de $300^{\circ} \mathrm{C}$, apesar de, em ambientes naturais, serem esperadas temperaturas menores (Frey 1970).

Discussão Em geral, verifica-se, para $\mathrm{Dn} / \mathrm{Mn}$, uma forte diferença entre os minerais marcadores de metamorfismo e a mecânica de deformação atuantes nas rochas da Formação São Joaquim, em relação às rochas do restante do Gráben de Martinópole. Os litotipos dessa Formação evidenciam urna componente de cisalhamento muito forte, com instalação de estruturas de empurrão do tipo duplex, cujo pico metamórfico alcança a fácies anfibolito superior de pressões intermediárias, o que denota um nível crustal relativamente profundo. Os metassedimentos do Grupo Martinópole e do São José, ao contrário, exibem estilos de deformação bem mais simples, ou seja, apenas xistosidade/clivagem ardosiana em dobramentos comuns, com pico de metamorfismo atingindo no máximo a porção mediana da fácies xisto-verde, sobretudo em fácies prehnita-pumpellyíta de pressões baixas, por correspondência localizadas em níveis crustais muito mais rasos.

Mediante as diferenças dos dados acima, é bastante sugestivo tratar-se de uma discordância tectonometamórfica situada entre as litologias pertencentes ao Gráben de Martinópole, com referência às da Formação São Joaquim. Outra possibilidade é a de que essa diferença denotaria evoluções tectonometamórficas de diferentes períodos. Nesse caso, a referida Formação possuiria uma fase tectônica anterior ao preenchimento do Gráben e, por conseguinte, a fase tectânica principal dessas unidades estaria relacionada com uma evolução muito mais nova.

FASE $_{(\mathbf{n}+1)}$ Estruturas Caracterizada por uma clivagem ardosiana nos Metassedimentos de Casinha, bem como por foliações fracas (ao microscópio) e clivagem espaçada locais no restante das rochas do Gráben estudado. No embasamento há evidências de dobras fechadas e recumbentes, com clivagem de fraturas associadas. Nos quartzitos da Formação São Joaquim, essa fase denota dobras abertas com planos axiais de clivagem de fraturas ou ainda uma fraca clivagem de crenulação (Fig. 6). As estruturas contínuas possuem atitudes E-W no centro do Gráben, rotacionando para NE-SW nos extremos. Em geral a lineação é subhorizontal, e a foliação revela mergulhos altos.

Metamorfismo A influência dessa fase metamórfica é mais bem notada nos xistos basais e nas cálcio-silicáticas da Formação São Joaquim. Nos xistos, é possível observar as seguintes associações mineralógicas: plagioclásio $(\mathrm{An}=11 \%)$ /quartzo/ biotita/opacos, muscovita/biotita/quartzo, além de clorita/ quartzo/biotita. Tais associações mineralógicas evidenciam um 

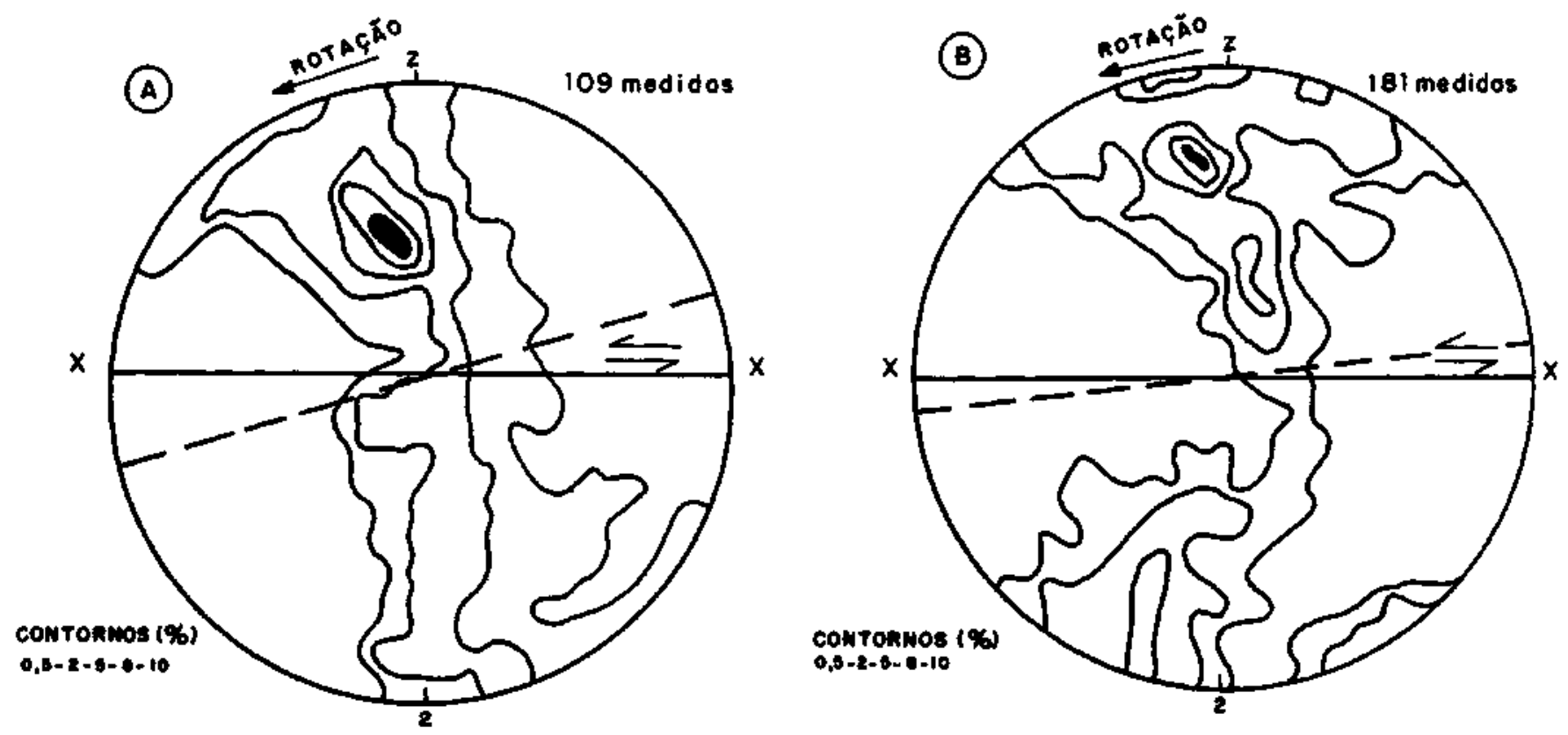

Figura 9 - Guirlandas "faixa máxima" de eixo c de quartzo. Notar a rotação dos "esqueletos" no estereograma (ver texto). Quartzitos da Formação São Joaquim: A. noroeste da localidade de Paula Pessoa, 109 medidas; B. sudeste da localidade de Paula Pessoa, 181 medidas. Cortes XZ. Rede de Wulff. Contornos de 0,5-2-5-8-10\%

Figure 9 - Diagrams of "maximum belt type" of quartz c axis. Note the rotation of the "skeletal form" on stereogram (see text). São Joaquim Formation quartzites. A. Northwestern of Paula Pessoa locality, 109 measures; B. Southeastern of Paula Pessoa locality, 181 measures. XZcut plane. Wulff net, 0,5-2-5-8-10\%

metamorfísmo de faties xisto-verde em sua porção superior, na zona da biotita (Hyndman 1972).

Nas cálcio-silicáticas, são reconhecidas as seguintes asso ciações mineralógicas: tremolita/quartzo/opacos e carbonato/ cloríta (clinocloro)/quartzo/opacos. Na discussão dessas paragêneses, verifica-se que a isógrada indicada para a formação de tremolita inicia-se a aproximadamente $400^{\circ} \mathrm{C}$, com pressões de $2 \mathrm{kbar}$, e $\mathrm{Xco}_{2}=0,25$, ou cerca de $500^{\circ} \mathrm{C}$, no caso da $\mathrm{Xco}_{2}$ aumentar até $100 \%$ (Hyndman 1972).

No restante dos metassedimentos do Gráben de Martinópole, verifica-se basicamente o desenvolvimento de mica branca e clorita, o que, em geral, caracteriza a porção inferior da fácies xisto-verde. Sob um outro ponto de vista, os Metassedimentos de Casinha foram analisados com base em suas características texturais (comparações com estudos desenvolvidos por Frey 1970, 1987 e Juster 1987), através das quais evidencia-se uma passagem de anquimetamorfismo para o metamorfísmo propriamente dito.

Discussão À semelhança do metamorfísmo já caracterizado na fase $\mathrm{Dn}$, a fase $\mathrm{D}_{\mathrm{n}+1}$ denota uma forte diferença no reconhecimento do estágio de estruturação e metamorfismo entre os Metassedimentos de Casinha (estes possuem seixos pré-foliados das unidades subjacentes) e as unidades estratigráficas inferiores do Gráben de Martinópole.

Também na fase $D_{n+1} / M_{n+1}$ há confirmação da discordância tectonometamórfica (já discutida anteriormente) entre a Formação São Joaquim e as unidades do Gráben de Martinópole. Para a Formação, verifica-se um pico de metamorfísmo em fácies xisto-verde superior, enquanto para as demais litologias, aparecem apenas minerais de metamorfismos correlates à fácies prehnita-pumpellyiíta.

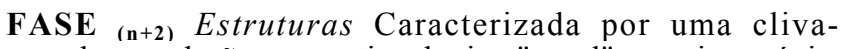
gem de crenulação penetrativa do tipo "zonal", ao microscópio, como também por dobras chevron, geralmente centimétricas, de planos axiais verticais, todos inseridos nos metassedimentos de baixo grau do Gráben de Martinópole.
Metamorfísmo No embasamento, esse processo foi instalado pela hidratação dos feldspatos em processos de saussuritização, com metamorfismo em fácies xisto-verde inferior, sobretudo de acordo com a seguinte reação (de Braun 1974):

\section{An plagioclásio + feldspato patássico +2 hidróxido de $\mathrm{Fe}+\mathrm{CO}_{2} \rightleftarrows$ calcila + mica branca + opacos + quarzo.}

Nos xistos da Formação São Joaquim, acha-se representado pela desestabilização de almandina para clorita/opacos/mica branca/ hidrobiotita bem como pela associação de hidrobiotita com albita. As reações que regem a formação das associações acima são, provavelmente, em caráter retrógrado às da formação da própria granada, ajustadas à presença de fluidos em um novo ambiente metamórfico (Turner 1987). Por fim, no Grupo Martinópole, no São José e ainda nos Metassedimentos de Casinha, o metamorfismo encontra-se fracamente registrado apenas na instalação de zonas de cisalhamentos regionais com processos de hidratação.

No total da área, as fases de metamorfísmo $\left({ }_{n+1}\right)$ e $\left({ }_{n+2}\right)$ refletem um retrometamorfismo em relação às fases anteriores, como pode ser visto esquematicamente na representação dos metamorfismos de todas as fases na figura 11 .

FASE ${ }^{(\mathbf{n}+3)}$ Tal fase não caracterizou metamorfísmo, exibindo apenas microcisalhamentos, dobras em estágio frágil, ondulações a dobras nos sedimentos do Grupo Jaibaras, além de feições frágeis de reativações das zonas de cisalhamento Dn. É interpretada como uma representação do soerguimento crustal que provocou reativações dos cisalhamentos regionais ativos por todo o Fanerozóico.

CONCLUSÕES A partir do presente trabalho, algumas conclusões foram levantadas, muitas delas comentadas de forma detalhada em Oliveira (1987), embora a grande maioria tenha sido agora reavaliada, sob o enfoque da geologia regional do Gráben de Martinópole. 


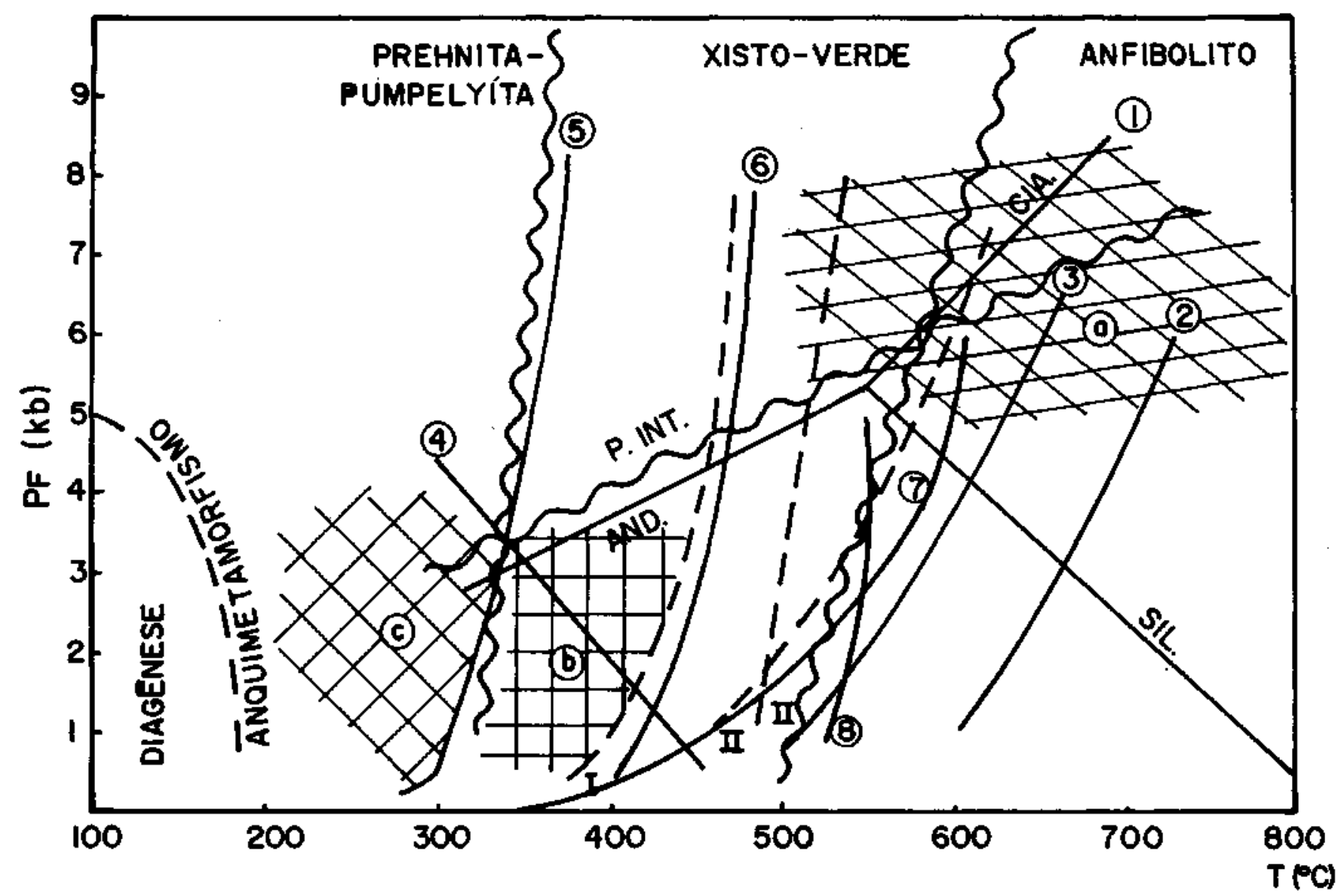

Figura 10 - Diagrama P x T para o metamorfismo da área de mapeamento, mostrando as isógradas das principais reações caracterizadoras: a. Mn na Formação São Joaquim; b. Mn no Grupo Martinópole e no São José; c. $M_{n+1} / M_{n+2}$ nas demais rochas do Gráben de Martinópole. Isógradas: 1. Silicatos de alumínio (média de vários autores, adaptado de Mueller \& Saxena 1977); 2. feldspato potássico (Day 1973, apud Mueller \& Saxena 1977); 3. e 7. diopsídio (Hyndman 1985, Fig. 12.10); 4. pirofilita (Velde 1969, apud Hyndman 1972); 5. pirofilita (Thompson 1970, apud Miyashiro 1973); 6. biotita (Winkler 1976); 8. almandina (Hsu 1968, apud Hyndman 1985). I e II. limites da estabilidade superior da pirofilita (respectivamente Kerrick 1968 e Althaus 1966, apud Mueller \& Saxena 1977); III. limite superior da estabilidade da paragonita (Winkler 1976)

Figure 10 - P x T diagram of metamorphism for the mapped area. It shows the isograds of the principal characterized mineral reactions: a. Mn for São Joaquim Formation; b. Mn for Martinópole Group and São José Group; c. $\mathrm{M}_{\mathrm{n}+1} / \mathrm{M}_{\mathrm{n}+2}$ for the other lithologies of the Martinópole Gráben. Isograds: 1. aluminum silicates (average of several authors, adapted from Mueller \& Saxena 1977); 2. potassium feldspar (Day 1973, apud Mueller \& Saxena 1977); 3. and 7. diopside (Hyndman 1985; Figure 12.10); 4. pyrophyllite (Velde 1969, apud Hyndman 1972); 5. pyrophyllite (Thompson 1970, apud Miyashiro (1973); 6. biotite (Winkler 1976); 8. almandine (Hsu 1968, apud Hyndman 1985). I. and II. upper boundaries of pyrophyllite stability (respectively Kerrick 1968 and Authaus 1966, apud Mueller \& Saxena 1977); III. upper boundary of paragonite stability (Winkler 1976)

Estratigraficamente, o local estudado apresenta-se, da base para o topo, como: embasamento Complexo Gnáissico-Migmatítico; Formação São Joaquim, desmembrada da evolução sedimentar do Gráben de Martinópole e redefinida (com xistos na Unidade I, basal, e quartzitos na Unidade II); Grupo Martinópole, redefinido para rochas oriundas tipicamente de vulcanoclásticas e permanecendo ainda subdividido na Formação Covão, basal, e na Santa Terezinha; Grupo São José, formado por seqüências de rochas siliciclásticas; Metassedimentos de Casinha (diamictitos de idades sin a pós-Grupo Ubajara); Grupo Jaibaras, constituído por molassas tardibrasilianas (subdividido na Formação Massapê, basal, e na Pacujá), além das Coberturas Cenozóicas.

O Complexo Gnáissico-Migmatítico encontra-se sob uma discordância estrutural com as rochas sobrepostas, possuindo, dessa forma, exclusivamente a fase $\mathrm{D}_{\mathrm{n}-1}$, o que lhe confere a condição de embasamento.

A Formação São Joaquim foi subtraída do Grupo Martinópole, tomando-se, assim, uma unidade estratigráfica indepen- dente, acrescida de uma seqüência xistosa basal (Unidade I) e seguida estratigraficamente pelos quartzitos (Unidade II). Recentemente Pedreira \& Torquato (1991), com uma abordagem regional, reforçaram os argumentos apresentados anteriormente por Oliveira (1987), com respeito ao referido desmembramento entre as duas unidades.

A relação estratigráfica entre o Grupo Martinópole e o São José na área mapeada ainda é incerta, uma vez que tais grupos definem contatos falhados entre si. Ó Grupo Martinópole caracteriza vulcanoclastitos; já o São José foi reinterpretado como tipicamente siliciclástico.

Uma discordância tectonometamórfica muito marcante (sobretudo na fase $\mathrm{Dn} / \mathrm{Mn}$ ) desenvolveu-se entre os litotipos que compõem a Formação São Joaquim, com relação às rochas do restante do Gráben, o que evidencia a incompatibilidade estratigráfica entre essas rochas. A referida Formação denota um pico de metamorfismo em fácies anfibolito superior com pressão intermediária, enquanto as outras unidades revelam minerais formados da fácies prehnita-pumpellyíta à xisto-ver- 


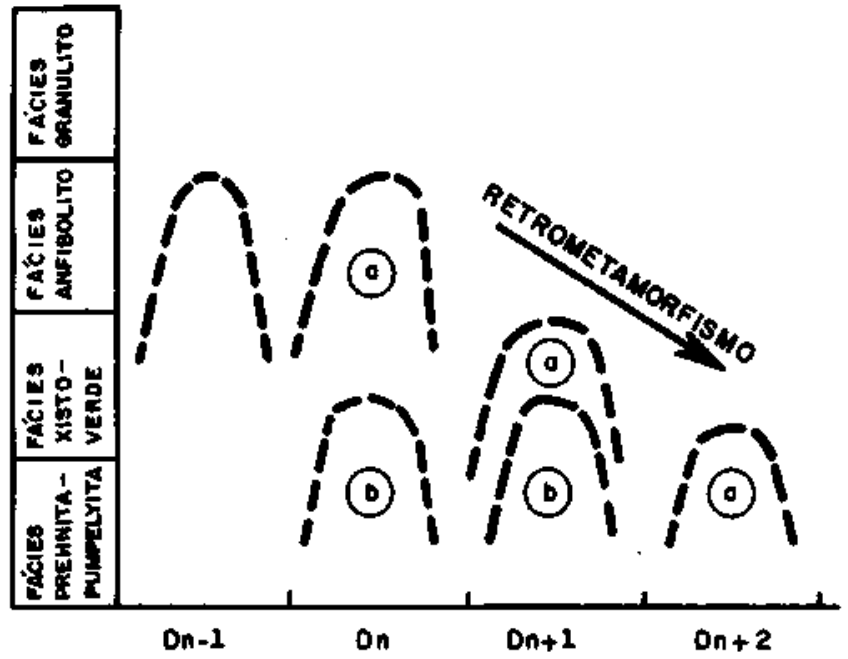

(a) ronmacio sxo nonoulm

\section{(b) METASSEDNENTOS RESTANTES}

Figura 11 - Esquema da evolução das fades metamórficas em relação aos eventos deformativos (ver texto). Notar a discordância metamórfica e o retrometamorfismo. $D_{n+1}$ e $D_{n+2}$ denotam uma evolução progressiva

Figure 11 - Schematic evolution of metamorphic facies in relation to the deformation phases (see text). Note the metamorphic unconformity and the retrograde metamorphism. $D_{n+1}$ and $D_{n+2}$ show a progressive evolution

de inferior, refletindo, desse modo, uma diferença de nível crustal, posicionada no mesmo patamar topográfico atual, pelo sistema de falhas normais/cisalhamento do final do Ciclo Brasiliano.

Os Metassedimentos de Casinha constituem uma unidade informal, que desenvolveu uma discordância estrutural com as unidades subjacentes, em virtude de não ser afetada por Dn (ou seja, possui seixos préfoliados Sn das rochas situadas estratigrafícamente abaixo). Essa unidade era mapeada normalmente como Grupo Martinópole por outros autores. Com reservas, todavia, pode ser correlacionada com a Formação Olho d'Água do Caboclo, de Hackspacher et al. (1988).

Nessa área ocorrem duas pequenas pull-aparts preenchidas por cunhas elásticas molássicas relacionadas com o Ciclo Brasiliano: o Gráben de Jaguarapi (extremo noroeste), composto da Formação Massapé e da Pacujá, e o Gráben do centronordeste, constituído pela Formação Massapé. É muito provável que essas pequenas pull-aparts (raramente mapeadas) sucedam por todo o Gráben de Martinópole, devido a forte influência do sistema de falhas/cisalhamento presente no final do Brasiliano.

A área estudada mostra uma alta complexidade, no que concerne à evolução tectonometamórfica. Foram constatadas cinco fases de dobramentos com quatro metamorfismos associados, a saber: $\mathrm{D}_{\mathrm{n}-1}$, anfibolito superior no embasamento (Ciclo Jequié ??); Dn, parte em prehnita-pumpellyíta/xisto-verde inferior e parte em anfíbolito superior, com pressões intermediárias (Ciclo Transamazânico); $\mathrm{D}_{\mathrm{n}+1}$, parte em prehnitapumpellyita e parte na porção mediana de xisto-verde (Ciclo Brasiliano); $\mathrm{D}_{\mathrm{n}+2}$, em fácies xisto-verde e nos Metassedimentos de Casinha, onde é impressa a passagem de anqui-metamorfismo para o metamorfismo (também Brasiliano); por fim, $\mathrm{Dn}^{+3}$, sem desenvolvimento de metamorfismo (tardibrasiliano). É sugestivo que as fases finais $\left(D_{n+1}, D_{n+2}\right.$ e $\left.D_{n+3}\right)$ tenham sido desenvolvidas em progressão de um mesmo evento deformativo de grande expressão.

Agradecimentos O autor agradece ao prof. dr. Peter C. Hackspacher, por ter lhe apresentado a área estudada, como também a orientação e a solicitude no decorrer do trabalho. Ao prof. dr. Jean M. Legrand a revisão crítica e as sugestões para o manuscrito. Ao relator(a) anônimo da RBG as críticas e as sugestões ao trabalho, e ainda a Marina B. Gaino a ajuda na sua preparação e a Eliane Quintão a revisão bem como a digitação do texto. Este trabalho contou com suporte financeiro do CNPq/ UFRNDG.

\section{REFERÊNCIAS BIBLIOGRÁFICAS}

ABREU, F.A.M.; GAMA, T., Jr.; GORAYEB, P.S.S.; HASUI, Y. 1988. O Cinturão de Cisalhamento Noroeste do Ceará. In: CONGR. LAT. AMER. GEOL., 7. Belém, 1988. Anais... Belém, SBG. v.l, p. 20-34.

ABREU, F.A.M. \& LAFON, J.M. 1991. Granulitos transamazônicos no Cinturão de Cisalhamento Noroeste do Ceará. In: SIMP. GEOL. NORDESTE. 14. Recife, 1991. Atas... Recife, SBG. p. 229-231. (Boletim 12)

ALMEIDA, F.F.M.; HASUI, Y.; NEVES, B.B.B.; FUCK, R. A. 1977. Províncias estruturais brasileiras. In: SIMP. GEOL. NORDESTE, 8. Campina Grande, 1911. Atas... Campina Grande, SBG. p. 363-391.

BLACK, R.; CABY, R.; MOUSSINE-POUCHKINE, A.; BAYER, R.; BERTRAND, J.M.; BOULLIER, A.M.; FABRE, J.; LESQUER, A. 1979. Evidence for late Precambrian plate tectonics in West Africa. Nature, 288(5701):223-227.

BRAUN, E. 1974. Mikrosondenuntersuchungen von saussuriten in abhangigkeit von metamorphograde und von geochemischen millieu. Contr. Mineral. Petrol., 46:301-327.

CABY, R.; BERTRAND, J.M.L.; BLACK, R. 1981. Pan-African ocean closure and continental colisions in the Hoggar, Iforas segment, central Sahara In: KRONER, A. ed. Precambrian Plate Tectonics. Developments in Precambrian Geology. Amsterdam, Elsevier. № 4, p. 407-434

CARSON, M.S. \& MITCHELL, A.H.G. 1982. Precambrian ore deposits and plate tectonics. In: KRONER, A. ed. Precambrian Plate Tectonics. Developments in Precambrian Geologv. Amsterdam, Elsevier. $\mathrm{n}^{\circ} 4$, p. 689-722.

CHRISTIE-BLICK, N.; GROTZINGER, J.P.; BORCH, C.C. 1988. Sequence stratigraphy in proterozoic sucessions. Geology, 16:100-104.

COMPANHIA AUSTRAL.1980. Projeto Ceará. Salvador, Caraíba Metais. 120 p. (Relatório Interno)

CONDIE, K.C. 1982a. Plate Tectonics and Crustal Evolution. New York, Pergamon Press. $310 \mathrm{p}$.

CONDIE. K.C. 1982b. Early and Middle Proterozoic supracrustal sucessions and tectonics settings. Am. J. Sci., 282:341-357.
COSTA, MJ · FRANCA, J.B · LINS, C. A.C; BACHIERA, IF · CRUZ, W.B. HABECOST, C.R. 1973. Projeto Jaibaras, Mapa Geológico 1:250.000. Recife, DNPM/CPRM. 120 p.

COWARD, M.P. 1983. Trust tectonics, thin-skinned or thick-skinned, and the continuation of thrust to deep in the crust. J. Struc. Geol., $\mathbf{5}(2): 113-123$

FREY, M. 1970. The step from diagenesis to metamorphism in pelitic rocks during alpine orogenesis. Sedimentology, 15:261-279.

FREY, M. 1987. Very low-grade metamorphism of clastic sedimentary rocks. In: FREY, M. Low Temperature Metamorphism. New York, Blackie. p. $9-58$

GALE, G.H. 1983. Proterozoic exhalative massive sulphide deposits. In: MEDARIS, L.G., Jr. et al. Proterozoic geology: select papers from an International Proterozoic Symposium. Geol. Soc. Amer. 161:191-207. (Memoir).

GORAYEB, P.S.S. \& ABREU, F.A.M. 1989. A faixa de alto grau da região de Cariré-CE. In: SIMP. GEOL. NORDESTE, 13. Fortaleza, 1989. Atas... Fortaleza, SBG. p. 261-264.

GORAYEB, P. S. S. TAVARES, S. S, Jr.; LAFON, JM. 1991. Novos dados geocronológicos na região entre Forquilha e Santa Quitéria - NW do Ceará. In: SIMP. GEOL. NORDESTE, 14. Recife, 1991. Atas... Recife, SBG. p. 260-263. (Boletim 12).

HACKSPACHER, P.C. 1989. O significado das estruturas tipo bainha. In: SIMP. GEOL. NORDESTE., 13. Fortaleza, 1989. Atas... Fortaleza, SBG. Bol. 11, p. 225-228

HACKSPACHER, P.C.; SANTOS, T.J.S.; LAFON, J.M. 1991. Evolução geocronológica do Complexo Gnáissico-Migmatítico - NW do Ceará. In: SIMP. GEOL. NORDESTE, 14. Recife, 1991. Atas... Recife, SBG. Bol. 12, p. 268-271.

HACKSPACHER, P.C.; SOARES, J.S.; PETTA, R.A. 1988. Geologia do Grupo Ubajara, região de Frecheirinha (CE). In: CONGR. BRAS. GEOL., 35. Belém, 1988. Anais... Belém, SBG. v. 6, p. 2661-2677. 
HOLDAWAY, M.J. \& LEE, S.M. 1977. Fe-Mg cordierite stability in high-grade pelitic rocks based on experimental, theorical, and natural observations. Contr. Mineral. Petrol., 63:175-198.

HUTCHINSON, R.W. 1982. Metallogenic evolution and precambrian tectonics. In: KRONER, A. ed. Precambrian Plate Tectonics. Developments in precambrian geology. Amsterdam, Elsevier. p. 733-753.

HYNDMAN, D.W. 1972. Petrology of Igneous andMetamorphic Rocks. New York, McGrawHill. 533 p.

HYNDMAN, D.W. 1985. Petrology of Igneous and Metamorphic Rocks. 2 ed. New York, McGrawHill. $786 \mathrm{p}$

JANSEN, J.B.H.; KRAATS, A.H.; RIJTS, H.; SCHUILING, R.D. 1978. Metamorphism of silicious dolomites at Naxos, Greece. Contr. Mineral. Petrol., 67:279-288.

JUSTER, T.C. 1987. Mineralogic domains in very low grade pelitic rocks. Geology, 15:1010-1013.

KEGEL, W.; SCORZA, E.P.; COELHO, F.C.P. 1958. Estudos Geológicos no Norte do Ceará. Rio de Janeiro, DGM/DNPM. p. 01-46. (Boletim 184)

LAJOIE, J. 1980. Volcanoclastic rocks. In: WALKER, R.G. Facies Models. Geosciences Canada. 1:191-200 (Serie Reimpression).

LISTER, G.S. \& HOBBS, B.E. 1979. The simulation of fabric development during plastic deformation and its application to quartzite: the influence of deformation history. J. Struc. Geol, 1:283-297.

MIYASHIRO, A. 1973. Metamorphism and Metamorftc Belts. 5 ed. London, George Accen \& Unwin. 492 p.

MOSHER, S. \& HELPER, M. 1988. Interpretation of polydeformed terrenes. In: MARSHAK, S. \& MITRA, G. ed. Basic Methods of Structural Geology. Englewood cliffs, Prentice-Hall, p. 361-384.

MUElleR, R.F. \& SAXENA, S.K. 1977. Chemical Petrology, with Application to the Terrestrial Planets and Meteorites. New York, Springer-Verlag. 396 p.

NEVES, B.B.B. 1975. Regionalização Geotectônica do Pré-Cambriano do Nordeste. São Paulo. 198 p. (Tese de Doutoramento, IG/USP).

NOVAIS, F.R.G.; NEVES, B.B.B.; KAWASHITA, K. 1979. Reconhecimento cronoestratigráfico na região noroeste do Ceará. In: SIMP. GEOL. NOR-

DESTE, 9. Natal. Atas... Natal, SBG. p. 93-110.

OLIVEIRA, D.C. 1987. Contribuição ao Estudo da Geologia do Noroeste do Ceará - Mapeamento Geológico de uma Area ao Sul de Granja (CE). Natal, DG/UFRN. 232 p. (Relatório de Graduação).

OLIVEIRA, D.C.; HACKSPACHER, P.C.; PETTA, R.A. 1988. Relações estruturais do Grupo Martinópole e do Grupo São José (NW-CE). In: CONGR. BRAS. GEOL., 32. Belém, 1988. Anais... Belém, SBG. v. 6 , p. 2765-2777.
PEDREIRA, L.H.S.T. \& TORQUATO, J.R. 1991. Formação São Joaquim. Base do Grupo Martinópole ou Grupo São Joaquim? In: SIMP. GEOL. NORDESTE, 14. Recife, 1991. Atas... Recife, SBG. Bol. 12, p. 26-29.

PETTA, R.A. HACKSPACHER, P.C.; FIGUEIREDO, O.A., P 1989. A tectônica transcorrente do Grupo São Joaquim no NW do Ceará. In: SIMP. GEOL. NORDESTE, 2. Fortaleza, 1989. Atas... Fortaleza, SBG. Bol. 11, p. 245.248 .

PRADO, F.S.; MENDONÇA, J.C.G.S.; MORAIS, J.B.A.; MEDEIROS, M.F.; ASSUNCÃO, P.R.S.; ANDRADE, V.A.; MEDEIROS, R.P. 1981. Geologia da Região Noroeste do Estado do Ceará. Projeto Martinópole. Brasília, DNPM/CPRM. p. 59, (Série Geologia Básica 17).

PROJETO RADAMBRASIL. 1981. Levantamento de Recursos Naturais, Folha SA-24. Fortaleza/Rio de Janeiro, MME/SG. v. 1, 487 p.

RAMSAY, J.G. \& HUBER, M.I. 1983. The Tecniques of Modem Structural Geology. Strain Analysis. Academic Press, v. 1,307 p.

SÁ, E.F.J. 1984. Evolução proterozóica da Província Borborema. In: SIMP. GEOL. NORDESTE, 11. Natal, 1984. Atas... Natal, SBG. p. 297-316.

SÁ, E.F.J. \& HACKSPACHER, P.C. 1982. Revisão sobre análise estrutural, parte 1 - conceituação básica e métodos. Ciências da Terra, 5:24-36.

SANTOS, E.J. \& NEVES, B.B.B. 1984. Província Borborema. In: ALMEIDA, F.F.M. \& HASUI, Y. ed. O Precambriano do Brasil. São Paulo, Edgard Blücher Ltda. p. 123-186.

SIAL, A.N.; FIGUEIREDO, M.H.; LONG, L.E. 1981. Rare Earth element geochemistry of the Meruoca and Mocambo plutons, Ceará, Northeast Brazil. Chem. Geol., 31:271-283.

SOARES, T.J.S. 1988. Contribuição ao Estudo Geológico da Região Noroeste do Ceará - Mapeamento Geológico de uma Área a Sudoeste de Granja (CE) - Area de Pitimbu. Natal, DG/UFRN. 126 p. (Relatório de Graduação).

TURNER, F.J. 1987. Metamorphic Petrology. Mineralogical, Field and Tectonic Aspects. 2 ed. New York, MacGrawHill. 542 p.

WINDLEY, B.F. 1986. The Evolving Continents. 2 éd. Avon, Wiley \& Sons. 399 p.

WINGE, M. 1967. Breves Notas sobre a Geologia do Noroeste do Ceará. Recife, EDG/SUDENE. p. 14-23 (Boletim 03).

WINKLER, H.G.F. 1976. Petrogênese das Rochas Metamorficas. São Paulo, Edgard Blucher. $257 \mathrm{p}$

MANUSCRITO A719

Recebido em 26 de fevereiro de 1992

Revisão do autor em 15 de abril de 1992

Revisão aceita em 17 de abril de 1992 